\title{
TERRESTRIAL ECOSYSTEM RESPONSES TO GLOBAL CHANGE: A RESEARCH STRATEGY
}

\author{
Ecosystems Working Group
}

Environmental Sciences Division

Publication No. 4821

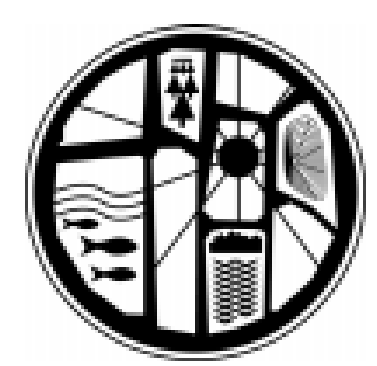


ENVIRONMENTAL SCIENCES DIVISION

TERRESTRIAL ECOSYSTEM RESPONSES TO GLOBAL CHANGE: A RESEARCH STRATEGY

Ecosystems Working Group

Environmental Sciences Division

Publication No. 4821

September 1998

Prepared for the U.S. DEPARTMENT OF ENERGY

Office of Biological and Environmental Research

Budget and Report Nos. KP 1203010 and KP 1203020

Prepared by the

OAK RIDGE NATIONAL LABORATORY

Oak Ridge, Tennessee 37831-6285

managed by

LOCKHEED MARTIN ENERGY RESEARCH CORP.

for the

U.S. DEPARTMENT OF ENERGY

under contract DE-AC05-96OR22464 



\section{PREFACE}

This report contains the recommendations of the Ecosystems Working Group on a research strategy to support the scientific information needs of global-change policy decision making. It presents a prioritization of research criteria and the rationale and design of a large-scale national program of ecosystem experiments. The members of the Ecosystems Working Group were as follows:

J. S. Amthor (co-chair)

V. H. Dale

N. T. Edwards

C. T. Garten

C. A. Gunderson

P. J. Hanson

M. A. Huston (co-chair)

A. W. King

R. J. Luxmoore

S. B. McLaughlin

G. Marland

P. J. Mulholland

R. J. Norby

E. G. O’Neill

R. V. O'Neill

W. M. Post

D. S. Shriner

D. E. Todd

T. J. Tschaplinski

R. S. Turner

G. A. Tuskan

S. D. Wullschleger 



\section{CONTENTS}

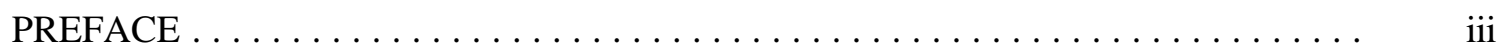

ABSTRACT $\ldots \ldots \ldots \ldots \ldots \ldots \ldots \ldots \ldots \ldots \ldots \ldots \ldots \ldots \ldots \ldots \ldots \ldots \ldots \ldots$

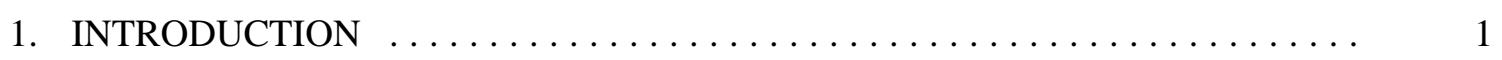

2. RATIONALE FOR EXPERIMENTS TO DEVELOP AND TEST

ECOSYSTEM MODELS $\ldots \ldots \ldots \ldots \ldots \ldots \ldots \ldots \ldots \ldots \ldots \ldots \ldots \ldots \ldots \ldots$

3. GENERAL EXPERIMENTAL DESIGN FOR TERRESTRIAL

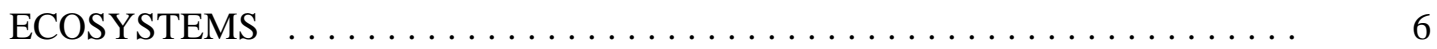

3.1 MULTISCALE, MULTIFACTOR ECOSYSTEM EXPERIMENTS . . . . . . . 6

3.2 TRANSIENT VS EQUILIBRIUM ECOSYSTEM DYNAMICS . . . . . . . . 7

4. OPTIMIZING THE EXPERIMENTAL PLAN $\ldots \ldots \ldots \ldots \ldots \ldots \ldots \ldots \ldots$

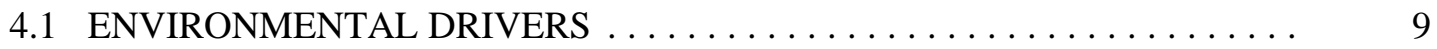

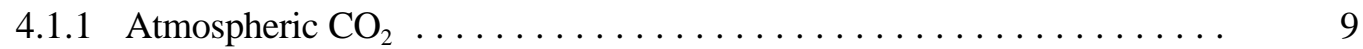

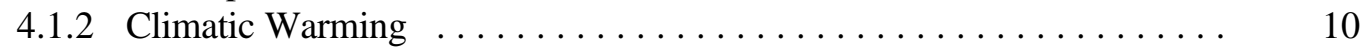

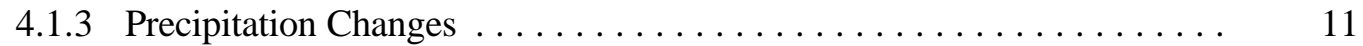

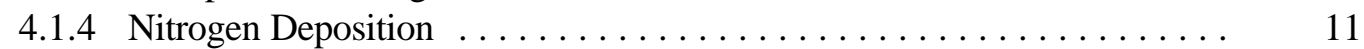

4.1 .5 Ozone . . . . . . . . . . . . . . . . . . . . . . . . . . . . . . . . 12

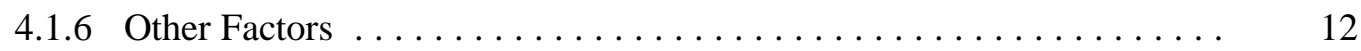

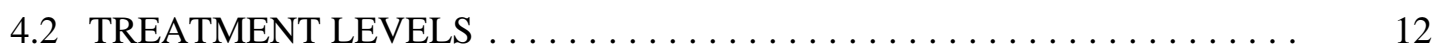

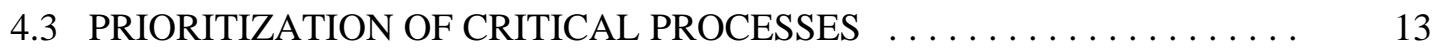

4.4 PRIORITIZATION OF CRITICAL ECOSYSTEMS $\ldots \ldots \ldots \ldots \ldots \ldots$.

5. RECOMMENDED HIGH-PRIORITY BIOMES AND EXPERIMENTAL

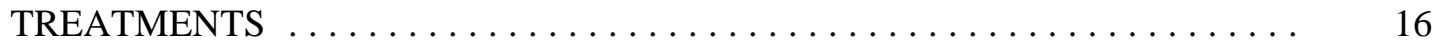

5.1 HIGH-LATITUDE TUNDRA, TAIGA, AND PEATLANDS $\ldots \ldots \ldots \ldots \ldots .16$

5.2 SEMIARID GRASSLANDS AND RANGELANDS $\ldots \ldots \ldots \ldots \ldots \ldots \ldots . \quad 18$

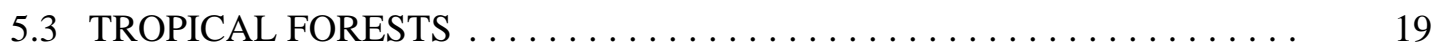

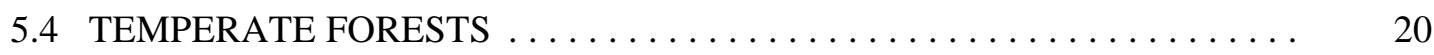

5.5 MAJOR FOOD CROPS (WHEAT, RICE, AND MAIZE) . . . . . . . 21

6. IMPLEMENTATION AND QUANTIFICATION OF EXPERIMENTAL

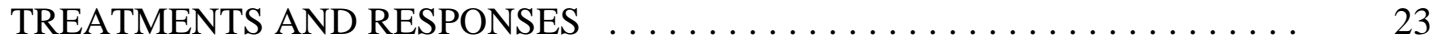

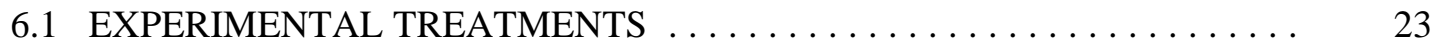

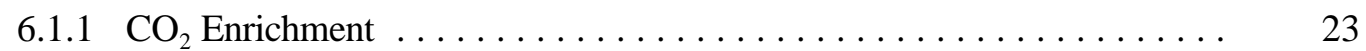

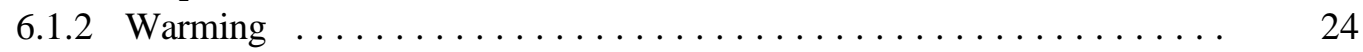

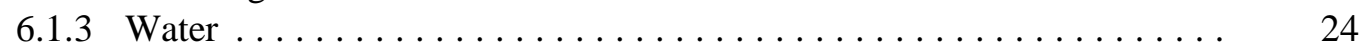

6.2 VERIFICATION OF TREATMENT AND QUANTIFICATION

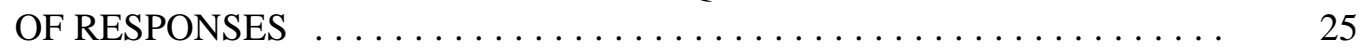

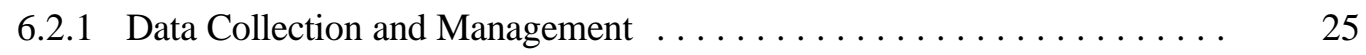

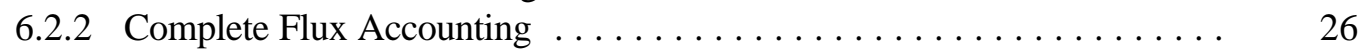




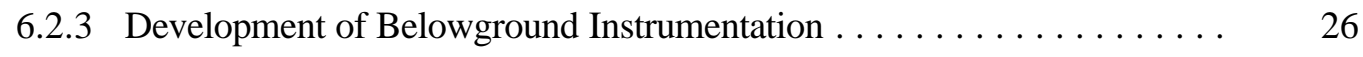

6.2.4 New Model Structures and Capabilities . . . . . . . . . . . . . . 26

7. RELATIONSHIP TO EXISTING RESEARCH PROGRAMS $\ldots \ldots \ldots \ldots \ldots \ldots$

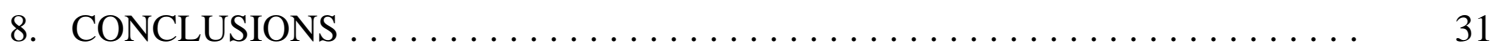

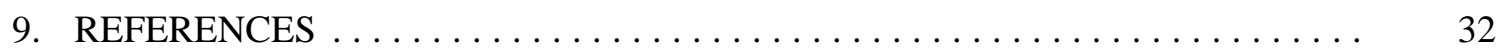




\begin{abstract}
Uncertainty about the magnitude of global change effects on terrestrial ecosystems and consequent feedbacks to the atmosphere impedes sound policy planning at regional, national, and global scales. A strategy to reduce these uncertainties must include a substantial increase in funding for large-scale ecosystem experiments and a careful prioritization of research efforts. Prioritization criteria should be based on the magnitude of potential changes in environmental properties of concern to society, including productivity; biodiversity; the storage and cycling of carbon, water, and nutrients; and sensitivity of specific ecosystems to environmental change.

A research strategy is proposed that builds on existing knowledge of ecosystem responses to global change by (1) expanding the spatial and temporal scale of experimental ecosystem manipulations to include processes known to occur at large scales and over long time periods; (2) quantifying poorly understood linkages among processes through the use of experiments that manipulate multiple interacting environmental factors over a broader range of relevant conditions than did past experiments; and (3) prioritizing ecosystems for major experimental manipulations on the basis of potential positive and negative impacts on ecosystem properties and processes of intrinsic and/or utilitarian value to humans and on feedbacks of terrestrial ecosystems to the atmosphere.

Models and experiments are equally important for developing process-level understanding into a predictive capability. To support both the development and testing of mechanistic ecosystem models, a two-tiered design of ecosystem experiments should be used. This design should include both (1) large-scale manipulative experiments for comprehensive testing of integrated ecosystem models and (2) multifactor, multilevel experiments for parameterization of process models across the critical range of interacting environmental factors $\left(\mathrm{CO}_{2}\right.$, temperature, water, nutrients). With limited resources, these complementary experiments should be focused in high-priority ecosystems, with experimental treatments designed to address the major uncertainties in each system.

Critical ecosystems, both managed and unmanaged, have been identified using the above criteria and key uncertainties in current understanding of ecosystem processes used to identify critical issues and experiments. The sizes of both the whole-ecosystem experiments and the multifactor experimental treatment units must be based on the sizes of the dominant organisms, the scale of major processes in each system, and the spatial heterogeneity of each system. For example, large-scale ecosystem manipulations in temperate forests should evaluate at a minimum $\mathrm{CO}_{2}$ and temperature and could be conducted on small, gauged catchments. The multifactor process experiments should address all major environmental driving variables, and the treatment units should be large enough to include multiple individuals of the major tree species.

This approach represents a fundamental shift in the scale and integration of experimental ecosystem research: from the current small-scale, single- or two-factor experiments in simple natural or artificial ecosystems to highly coordinated, large-scale, replicated experiments in complex ecosystems, with multiple interacting factors being evaluated at two (or more) complementary levels of spatial scale and process resolution. These experiments will require an unprecedented long-term funding commitment and concentration of large-scale experimental research at a few major sites, with significant new investment in infrastructure to support large interdisciplinary teams of scientists.
\end{abstract}




\section{INTRODUCTION}

During the past 250 years, atmospheric $\mathrm{CO}_{2}$ concentration has increased about $30 \%$, from less than 280 ppm to more than 360 ppm (Etheridge et al. 1996; Keeling and Whorf 1997; Marland et al. 1998). Given projected rates of fossil fuel use, it is expected that atmospheric $\mathrm{CO}_{2}$ concentration could reach 600 to 800 ppm during the next 100 years [e.g., Walker and Kasting 1992; Intergovernmental Panel on Climate Change (IPCC) 1996]. However, more accurate predictions of future atmospheric $\mathrm{CO}_{2}$ are not possible without a better understanding of future fossil fuel use, $\mathrm{CO}_{2}$ uptake by oceans, and the carbon balance of the terrestrial biosphere.

Increasing atmospheric $\mathrm{CO}_{2}$ is of concern mainly because it may be warming Earth's surface and could alter temporal and spatial patterns of precipitation and evaporation as a result of an enhanced global "greenhouse effect" (Easterling et al. 1997; IPCC 1996, 1998). However, it is not only $\mathrm{CO}_{2}$ and climate that are changing. Fossil fuel use is also contributing to increased levels and geographic extent of air pollutants, such as ozone in regions with heavy automobile traffic. In addition, deposition of nitrogen is reaching high levels in some agricultural areas and at high elevations downwind of major industrial and automotive sources.

The aggregate impacts of all of these changing conditions on the Earth's ecosystems are poorly understood and therefore difficult to predict. The primary difficulty stems from the many potential interactions among these environmental factors, which individually can have either positive or negative effects on many of the ecosystem properties and services important to human society. These complex interactions, many of which are nonlinear and can have effects that actually reverse under different conditions, have not been adequately resolved by the climate change and ecosystem research conducted over the past several decades [National Research Council (NRC) 1994].

For example, whereas it is widely accepted that the rapid increase in $\mathrm{CO}_{2}$ is mainly driven by fossil fuel use, atmospheric $\mathrm{CO}_{2}$ concentration is increasing less rapidly than would be predicted from known rates of fossil fuel use, deforestation, and $\mathrm{CO}_{2}$ uptake by the oceans (Houghton et al. 1990). Several lines of evidence, based on interhemispheric gradients in atmospheric $\mathrm{CO}_{2}$ concentration, intra-annual variations in models of ocean-atmosphere $\mathrm{CO}_{2}$ exchange, and the isotopic composition of atmospheric $\mathrm{CO}_{2}$, together suggest that the terrestrial biosphere of the northern hemisphere may be the sink for this "missing carbon" (Tans et al. 1990; Innes 1991; Quay et al. 1992; Kauppi et al. 1992; Bruno and Joos 1997).

One critical unknown that impacts both the global carbon cycle (including the location and strength of the "missing sink") and virtually all ecosystem processes and services is the process of " $\mathrm{CO}_{2}$ fertilization" of plant production. Some ecosystem studies have suggested that certain types of terrestrial vegetation are so strongly limited by other resources that, in the short term, they show little response to increases in atmospheric $\mathrm{CO}_{2}$ (Mooney et al. 1991; Oechel and Billings 1991). If this is the case, many of the future effects of climate change on ecosystem properties of value to society are likely to be negative. However, many greenhouse studies and some recent field studies of agricultural and natural ecosystems indicate that resource limitations may have only a minor effect on plant growth, so that vegetation and soils could sequester much of the $\mathrm{CO}_{2}$ added to the atmosphere by human activities (Curtis et al. 1989; Bazzaz 1990; Idso and Kimball 1991). Increased net primary productivity (NPP) and carbon storage are likely to have primarily positive effects on most ecosystem properties and services (Nicholls 1997).

At present, one of greatest uncertainties in predicting the future condition of the Earth's ecosystems, including biodiversity and the production of food and fiber, is understanding the 
interactions of simultaneously varying stresses and resources, particularly whether low nutrient or water availability is likely to constrain the response of ecosystems to elevated $\mathrm{CO}_{2}$ and temperature (NRC 1994, 1998; IPCC 1996, 1998). Until these issues are resolved, it will be difficult to provide reliable scientific guidance for policy decisions related to climate change.

To resolve these uncertainties and improve our ability to respond to changing environmental conditions, the National Research Council (NRC 1994) identified six major questions that should be addressed in order to understand the effects of global changes on terrestrial ecosystems and the effects that terrestrial ecosystems may have on climate:

(1) What are the interactive effects of changes in $\mathrm{CO}_{2}$, climate, and biogeochemistry on the terrestrial carbon cycle and on food and fiber production?

(2) What factors control trace-gas fluxes between terrestrial ecosystems and the atmosphere?

(3) What are reasonable scenarios of the future distribution, structure, and productivity of both managed and unmanaged ecosystems based on changes in land use, disturbance regime, and climate?

(4) How will global change alter biotic diversity and what are the ecosystem consequences?

(5) How will global change affect biotic interactions with the hydrologic cycle and surface energy balance?

(6) How will global change affect biotic controls over transport of water, nutrients, and materials from land to freshwater ecosystems and to coastal zones of the ocean?

Three elements of the global change research plan addressing the above six questions were highlighted for immediate action "because they are key components of the terrestrial research program that are unlikely to proceed without focused attention." This report addresses the first of these high-priority elements:

Experiments that determine ecosystem responses to interactions among elevated $\mathrm{CO}_{2}$, temperature, water, and nutrients. This program requires establishment of large-scale ... field experiments in selected managed and unmanaged ecosystems to determine how the response of entire ecosystems to elevated $\mathrm{CO}_{2}$ is constrained by temperature, water, and nutrients. The experiments required are well defined so that an experimental program can be implemented immediately. These are the most critical experiments required to improve our understanding of the response of terrestrial ecosystems to climate change and of the feedbacks to climate. Because of the expense and magnitude of these experiments, they cannot be implemented without focused attention (NRC 1994).

The following sections describe the rationale and design of a large-scale national program of ecosystem experiments designed to address this critical research objective. While the experiments focus on the first major question in the U.S. Global Change Research Program (USGCRP), they will provide information that will contribute to components of each of the six major questions identified for the USGCRP. 


\section{RATIONALE FOR EXPERIMENTS TO DEVELOP AND TEST ECOSYSTEM MODELS}

A central theme of many recent reviews of uncertainties related to climate change impacts is the need for development and use of integrated models of ecological and physical systems (NRC 1994, 1998; IPCC 1998). Current general circulation models, some of which include the surface biota in a highly abstracted fashion, have widely acknowledged deficiencies, and their ability to predict responses to unprecedented long-term changes is as yet untested. Nevertheless, these models represent the best available methodology for linking our small-scale understanding of ecological processes with our understanding of the large-scale processes determining climate.

There is general agreement that experiments are an essential tool in all sciences. However, there is much less agreement on the types and designs of experiments that are most useful for understanding the complex, large-scale environmental problems that increasingly confront society, such as global change. Because a hypothesis is simply a conceptual (or mathematical) model of what happens under specific conditions, experimentation and modeling are inextricably linked.

Every experiment can be interpreted in terms of how it contributes to the two primary components of modeling: model development (model structure that accurately represents key processes plus accurate parameterization of those processes) and model testing (verification of model design and performance and validation of model predictions for specific conditions against observations made under those conditions).

For example, automobiles are complex systems composed of many interacting parts that are required to function together to produce highly predictable responses under a wide range of conditions. Each component of an automobile is thoroughly tested, as a stand-alone unit, under a wide variety of experimental conditions that cover even the low-probability extremes that it might experience. However, no car ever goes into production without a second major set of experiments, the test drives of the assembled automobiles under a wide range of conditions. These experiments serve two primary purposes: (1) Determination of how the components respond as an integrated whole (including the quantification of performance factors, such as gas mileage and zero-to- 60 acceleration) and (2) evaluation of the original simulation model of the entire car to determine how well the integrated model predicted the observed performance in order to improve the models and their integration for the next round of design.

Whereas experiments at two different process levels are needed to design and test a model of a complex system, it is also true that almost any experiment can be interpreted at several levels. One level is as a reductionistic test of certain predictions of a mechanistic hypothesis about how some process responds to specific experimental conditions (e.g., fuel injector performance tests). Another level is as a holistic, empirical description of the effect of those specific experimental conditions on the net result of some incompletely understood set of interacting processes that produce some change in the state of a complex system (e.g., test drive performance evaluations).

Each approach, by itself, has inherent weaknesses that can only be overcome by a combination of both approaches. Detailed experiments on a specific process may not provide the information needed to understand how the interaction of that process with other simultaneous processes produces the result observed at a larger scale (e.g., a complex ecosystem). Similarly, quantification of the response of a large complex system to a specific set of conditions is unlikely to lead to predictions of how that system will respond to all possible sets of conditions, unless all processes that determine system behavior are well understood. Thus, no set of experiments at a 
single spatial scale or level of process resolution can provide BOTH a mechanistic understanding of processes at one scale and a test of the consequences of those same processes at a larger scale.

The critical issue in predicting ecological responses to environmental change (or to different environments) is to characterize processes in a manner that provides the most predictive power at the scales of response that concern society. The relevant scale of ecosystem response is the landscape or waterscape, where the production of food or wood products, or the conservation of biodiversity, operate and can be quantified. However, ecosystem responses at landscape scales are the aggregate of processes that occur among the component organisms of the ecosystem, interacting with their physical, chemical, and biotic environment at smaller scales.

Developing the capability to predict ecosystem responses to environmental change requires experiments at a minimum of two organizational levels in order to both develop and test ecological models: (1) the level of individual organisms, populations, and communities to quantify the responses of the mechanisms (growth, resource use, nutrient transformations, population dynamics) that aggregate to ecosystems; and (2) the level of the whole ecosystem to test the predictive capability of models that integrate multiple mechanisms across a complex and heterogeneous landscape (predator-prey dynamics, NPP and net ecosystem productivity (NEP), evapotranspiration and water yield, nutrient availability and loss, biodiversity).

The development and parameterization of models of the lower level processes that determine ecosystem dynamics (e.g., plant growth, competition and succession, reproduction and population dynamics, trophic interactions, hydrology, biogeochemical cycling, etc.) must be done in smaller scale experiments in which these component processes can be exposed to the full range of environmental conditions that they are expected to experience. Such experiments provide quantitative, empirical descriptions of the response dynamics of sub-ecosystem processes, as well as serving to test the predictions of mechanistic models based on processes that occur at still smaller scales and lower functional levels (e.g., models of plant growth and carbon allocation based on physiological processes).

Large, complex systems, such as ecosystems, cannot be treated as "black boxes" if we are to have any hope of predicting the future conditions of ecosystems around the world. It is simply not feasible to use experiments that are designed to manipulate entire landscapes or whole lakes to "parameterize" models of ecosystem response. The number of factors that influence ecosystems, as well as the variety of different ecosystem types, is so great that an "empirical" (or "phenomenological") model of ecosystem response dynamics is both conceptually and logistically intractable. The critical role of whole-ecosystem experiments is testing the integration of the submodels that comprise an ecosystem model not parameterizing models at any level.

Every local ecosystem is in some way unique. We can only demonstrate the power and generality of our understanding of ecological processes through accurately predicting the net consequences of universal processes operating under the constraints of specific local conditions. Models linked with experiments across a range of spatial scales and levels of process complexity provide the tools to achieve this goal. 


\section{GENERAL EXPERIMENTAL DESIGN FOR TERRESTRIAL ECOSYSTEMS}

\subsection{MULTISCALE, MULTIFACTOR ECOSYSTEM EXPERIMENTS}

The accomplishments and limitations of past experimental work on plant responses to climatic factors have been thoroughly reviewed (Kirschbaum 1996; IPCC 1996, NRC 1994, 1998). There is general agreement that we still lack an understanding of how plant growth and other ecosystem component processes respond over the full range of environmental conditions that we are likely to see in the future. Many single-factor experiments have been conducted but virtually no multifactorial, multilevel experiments that consider the nonlinear interactions among elevated carbon dioxide, alternative hydrologic regimes, different temperature scenarios, and variation in the availability of nitrogen and other limiting soil resources. Until such multifactorial experiments are conducted, it will continue to be impossible to test mechanistic models of plant growth, decomposition, evapotranspiration, and other processes that are influenced by multiple environmental conditions. We currently have no way to test the existing "mechanistic" models that are being used to predict biotic responses to climate change (Prentice et al. 1989; Running et al. 1989).

In addition to testing mechanistic models of sub-ecosystem processes, such multifactorial experiments will also provide quantitative "response surfaces" that describe the effect of multiple interacting environmental conditions on processes such as plant growth, leaf area, decomposition, etc. Such empirical response surfaces can be used as input into "mechanistic" ecosystem models based on these multiple interacting processes.

On the basis of the above considerations, the two-level series of experiments on ecosystem responses to climate change outlined in the 1994 NRC report, The Role of Terrestrial Ecosystems in Global Change: A Plan for Action, can be designed as follows:

(1) Large-scale, partial factorial experiments to test the ability of integrated, multiprocess ecosystem models to predict ecosystem responses to selected combinations of experimentally elevated $\mathrm{CO}_{2}$ and temperature, in the context of natural spatial and temporal variability in water, nutrients, and energy-related pollutants.

(2) Intermediate-scale, multifactorial experiments with experimentally controlled factor means and variabilities of the major interacting environmental conditions (i.e., $\mathrm{CO}_{2}$, temperature, water, nutrients, pollutants) to test mechanistic models of ecosystem component processes and to quantify the empirical responses of these processes to interacting environmental drivers.

Together, this set of experiments will (1) test existing mechanistic models of the response dynamics of sub-ecosystem processes; (2) develop quantitative input parameters (multidimensional response surfaces) for sub-ecosystem processes over the full range of anticipated environmental conditions; (3) test the ability of parameterized ecosystem models, based on multiple interacting processes operating under natural spatial and temporal variability, to predict ecosystem responses under specific conditions of elevated temperature and $\mathrm{CO}_{2}$; and (4) allow the interactive cycle of model development and testing that is necessary to advance our understanding of ecosystem responses to global change. 


\subsection{TRANSIENT VS EQUILIBRIUM ECOSYSTEM DYNAMICS}

A critical concern under conditions of relatively rapid environmental change is what will happen while ecosytems are "adjusting" to altered environmental conditions. When ecosystems are fully adjusted and "in equilibrium" with new environmental conditions, the global pattern may simply reflect spatial shifts in the geographical "zones" occupied by particular ecosystems. However, during the adjustment process it is possible that ecosystems may appear, and function, very differently than they do at present. Both the time period and the magnitude of such transient effects will vary greatly from one vegetation type to another.

Ecosystems dominated by relatively fast-growing herbaceous species, such as grasslands, are likely to adapt rapidly to altered environmental conditions, with little absolute change in standing biomass, which is relatively low originally. In contrast, ecosystems dominated by large, long-lived trees will adapt to new conditions much more slowly. The species composition of a forest may shift to a better-adapted group of species (or different morphological forms of the same species) either through a process of gradual change or a much accelerated rate of change associated with mortality of some of the existing species. Such mortality (which could also result from disturbances such as fires or windstorms) could greatly reduce the amount of living biomass, releasing additional $\mathrm{CO}_{2}$ into the atmosphere as dead trees decompose. Recovery of the biomass and carbon storage capacity of the forest would occur at the relatively slow rate of forest succession, which could take from 100 to 1000 years to achieve the same amount of carbon storage as the present forest. Presumably, the new forest that regrows following the mortality would be closer to an "equilibrium" with the new environmental conditions, but the transition to the new equilibrium would be relatively slow, with major perturbations to carbon storage and fluxes during the period of "transient dynamics." Similar, major perturbations to carbon storage and fluxes could also occur in non-forest systems, such as with the melting of permafrost and subsequent decomposition of organic matter that had been preserved by freezing.

Thus, we need to predict not only what the eventual "equilibrium" ecosystems of the future will look like, but also whether we can expect major disruptions in carbon storage and other critical ecosystem processes during the period of "transient dynamics." This requires two very different types of climate change experiments: (1) Exposure of existing, mature ecosystems to altered environmental conditions to evaluate processes that influence the rate of change in ecosystem properties; and (2) evaluation of the dynamics of ecosystem regeneration by allowing plant succession to occur under various combinations of environmental conditions. Mature ecosystems should be subjected to experimental manipulation in all priority ecosystem types. Succession experiments will be needed only in ecosystems with long turnover times (e.g., forests), where patterns of regeneration should give a good indication of the future "equilibrium" composition of the forest.

Whereas it is possible to expose entire ecosystems to extreme stresses that might cause mortality (e.g., Hanson et al. 1995, 1998), the primary concern is the possibility and potential effects of massive mortality of the dominant organisms. Experiments could focus on multiple individual organisms (e.g., large trees of the most abundant species) or relatively small plots of herbaceous vegetation to evaluate both the probability of mortality for existing vegetation as well as the potential for existing organisms to respond positively to altered environmental conditions through increased growth rates and carbon accumulation.

The need to understand transient dynamics, as well as the future equilibrium state of ecosystems, requires that some subset of these outlined partial-factorial large-scale experiments and the multifactorial intermediate-scale experiments outlined be repeated in mature vegetation. 
These experiments will obviously present a greater logistical challenge in large-statured vegetation than in grasslands, but it is in such large-statured vegetation that the potential impacts of transient dynamics are greatest. Equilibrium ecosystem conditions can be evaluated by allowing vegetation to regenerate (and other ecosystem processes to equilibrate) under the full factorial set of conditions. This regeneration will also provide important information on the "recovery phase" of transient dynamics if there is massive mortality of existing vegetation. 


\section{OPTIMIZING THE EXPERIMENTAL PLAN}

The design of any experiment in this research program must be focused toward specific questions and hypotheses and should build on our best current understanding of ecosystem responses to global change drivers. Even with unlimited resources, an efficient program to deliver policy-relevant answers in a reasonable time requires that research questions be prioritized and that the experimental approach for addressing them be optimized. Three main questions must be answered to rationalize and design any specific global change experiment. First, what are the most important environmental drivers to be studied in a given ecosystem? Second, how should those drivers be incorporated into an experimental manipulation? Third, how should the ecosystems for study be prioritized? Past (and ongoing) research provides considerable guidance in these matters, but a critical assessment needs to be conducted before new large-scale experiments are initiated. Preliminary experiments to test new approaches and protocols, especially in less well-developed research areas, such as whole-ecosystem warming, may also be appropriate.

\subsection{ENVIRONMENTAL DRIVERS}

For global change questions, the primary driving variables are increasing atmospheric $\mathrm{CO}_{2}$ concentration and climatic warming. Ecosystem responses to these drivers will often be modified by other global change factors, including changes in precipitation, nitrogen deposition, and tropospheric ozone. In addition, local landscape properties, such as the level and variability of soil fertility and water status or the age and species composition of the vegetation, will also affect the response of an ecosystem to global change drivers. The relative importance of these factors will vary among different ecosystems, and an efficient research program will focus on the most important interactions in a given system. It is important to recognize that existing spatiotemporal patterns of rainfall, soil moisture, and soil nutrients may change in the future, possibly beyond the range of existing conditions.

Results from past global change research demonstrate the importance of interactions between environmental factors in determining the integrated ecosystem response, and future research must focus on ecosystem responses to changes in multiple, interacting, and fluctuating environmental factors (Kirschbaum 1996; IPCC 1998; NRC 1994, 1998). Hypotheses about multifactor interactions will be derived from a fundamental understanding of the primary effects of each global change factor, and the design of complex experiments must be based on experience gained from single-factor manipulations.

\subsubsection{Atmospheric $\mathrm{CO}_{2}$}

The effects of elevated $\mathrm{CO}_{2}$ concentrations on plants are now well understood. Basically, elevated $\mathrm{CO}_{2}$ stimulates photosynthesis, and higher photosynthesis supports faster growth rates. The increased photosynthesis leads to various adjustments (secondary and tertiary responses) at the biochemical level, and the increased growth rates force various adjustments at the whole-plant level, as well as in the interaction of the plant with its environment. These adjustments, which are only partially understood, tend to modify but not replace the primary responses.

Recent larger-scale experiments under more natural field settings have generally supported what we had already learned from smaller-scale studies without producing any major surprises. 
Under most conditions, the stimulation of photosynthesis by elevated $\mathrm{CO}_{2}$ is sustained over time (Gunderson and Wullschleger 1994). This increase in photosynthesis, sometimes coupled with a reduction in respiration, generally leads to an increase in growth (Wullschleger et al. 1997; Norby et al. 1996; Curtis and Wang 1998). In long-lived perennial species, such as trees, increased growth implies an increase in carbon sequestration, at least for several decades. $\mathrm{CO}_{2}$ fertilization is thought to account for the uptake of 0.5 to $2.0 \mathrm{PgC}$ annually (IPCC 1996), and as the atmospheric $\mathrm{CO}_{2}$ concentration increases, this stimulation of plant uptake should increase as well, until the $\mathrm{CO}_{2}$ response is saturated.

The expression of growth responses in an unmanaged ecosystem will also depend on the interactive effects of $\mathrm{CO}_{2}$ and other environmental factors, particularly water and nitrogen, on canopy development and leaf area index. Increased photosynthesis, coupled with lower stomatal conductance, usually means that water-use efficiency (WUE) is increased in $\mathrm{CO}_{2}$-enriched plants. This response may increase the leaf area index and productivity in water-limited systems or allow the expansion of plants into arid or semiarid regions (Amthor 1995). Foliar nitrogen concentration is often lower in trees grown in high $\mathrm{CO}_{2}$ (Curtis 1996; McGuire et al. 1995), while photosynthesis and productivity per unit nitrogen is increased in high $\mathrm{CO}_{2}$ (increased nitrogen-use efficiency). This response cannot be sustained indefinitely as $\mathrm{CO}_{2}$ increases unless nitrogen availability also increases [Norby et al. 1986; Vegetation/Ecosystem Modeling and Analysis Project (VEMAP) Members 1995]. The many influences and feedbacks on carbon and nitrogen cycling in the soil (Zak et al. 1993) and the co-occurrence of rising $\mathrm{CO}_{2}$ with nitrogen deposition (Medlyn and Dewar 1996; Norby 1998) are key topics for determining the extent to which productivity gains in high $\mathrm{CO}_{2}$ will be constrained by the system's nitrogen budget. Different representations of the potential interaction of elevated $\mathrm{CO}_{2}$ with the nitrogen cycle were the primary reasons for differences between several models in their predictions of ecosystem response to $\mathrm{CO}_{2}$ (Ruimy et al. 1998). The responses of the nitrogen cycle in $\mathrm{CO}_{2}$-enriched ecosystems must be a high-priority research topic.

\subsubsection{Climatic Warming}

Atmospheric warming is the primary expected consequence of increasing greenhouse gas concentrations, and temperature affects virtually all biological and chemical processes. Much is already known about the responses of many individual processes to short-term increases in temperature, as well as the broad-scale patterns of ecosystem properties in relation to current patterns of global temperature. However, neither of these perspectives provides a clear guide to predicting future ecosystem-level responses to gradual increases in average temperature.

In contrast with the much simpler situation of elevated $\mathrm{CO}_{2}$, prediction of the response of ecosystems to atmospheric warming will require integration of both positive and negative effects on many disparate plant and soil processes. The critical processes to consider include heterotrophic respiration, autotrophic respiration, water balance, and phenology. Plant respiration is known to increase exponentially with increasing temperature, yet there is compelling evidence for acclimation of respiration to elevated temperature. Measurement of ecosystem carbon balance with eddy covariance approaches has shown that plant phenology is a primary cause of both interannual and regional differences in carbon uptake (Goulden et al. 1996). Observations at both the global scale (satellite imagery) and with individual plants have already demonstrated phenological responses to warming (Keeling et al. 1996).

The effects of warming are difficult to predict because temperature is not a simple variable. We must consider not only annual average temperature but also diurnal and seasonal variation, minima and maxima, and the stochastic element of stress-inducing temperature extremes. Changes 
in temperature necessarily imply a change in some expression of atmospheric moisture (humidity or vapor pressure deficit), and concurrent changes in precipitation will also have an important influence on ecosystem responses to warming.

It is also critical that the effects of elevated $\mathrm{CO}_{2}$ concentrations be evaluated in conjunction with elevated temperature (Long 1991). $\mathrm{CO}_{2}$ stimulation of photosynthesis is expected to be larger at higher temperatures, and elevated $\mathrm{CO}_{2}$ can mitigate against some of the negative effects of warming. Warming is expected to have large effects on soil systems. Nitrogen mineralization may be accelerated, possibly supporting a larger growth response to elevated $\mathrm{CO}_{2}$; but heterotrophic respiration should also increase, leading to losses of soil carbon from the ecosystem.

\subsubsection{Precipitation Changes}

General circulation model (GCM) predictions for precipitation change indicate large regional differences, ranging from large increases to large decreases. However, there is a high degree of uncertainty because the predictions of the different GCMs are not consistent. Reduced precipitation is expected to have a negative long-term impact, but this will depend on the current water balance of an ecosystem. The most important hydrologic property to consider in assessing potential terrestrial ecosystem responses to altered precipitation is soil water status. Soil water status is driven by the dynamic interaction between climatic conditions (precipitation and warming) and plant water use (as altered by elevated $\mathrm{CO}_{2}$ and warming).

In currently moist systems, the impact of reduced precipitation is tied to the periodicity of drought occurrence. Only when droughts are sustained over long periods will a cumulative impact on productivity and carbon gain be observed. However, sensitive species within such systems may be affected more severely by shorter-term water deficits. Future increases in precipitation to ecosystems that currently have sufficient rainfall inputs may lead to leaching of critical base cations over long time periods. Another issue related to increased incidence of precipitation is the effect of an increased cloudiness. Excessive cloudiness can reduce gross primary production (GPP), and the long-term impact on ecosystem carbon cycling will depend on the duration and degree of reduced light availability.

Ecosystems that are seasonally limited by soil-water deficits (woodlands, grassland, and desert systems) are expected to benefit most (in terms of overall carbon gain) from increased soil water inputs (as well as $\mathrm{CO}_{2}$-induced increases in water use efficiency). In some arid systems changes in the soil water balance may force changes in biodiversity that may or may not be favorable.

\subsubsection{Nitrogen Deposition}

Coincident with the release of $\mathrm{CO}_{2}$ from fossil fuels is the production of nitrogen oxides $\left(\mathrm{NO}_{\mathrm{x}}\right)$. Unlike the $\mathrm{CO}_{2}$, which is mixed fairly uniformly in the atmosphere, $\mathrm{NO}_{\mathrm{x}}$ and agricultural ammonia (NHx) are deposited back to terrestrial systems fairly quickly and relatively close to the source. These nitrogen compounds can serve as a fertilizer that enhances ecosystem productivity. Model estimates suggest that nitrogen deposition provides a sink for 1.5 to 2.0 Pg of carbon per year. This sink is located primarily in temperate, industrialized regions, based on the global distribution of deposition and the occurrence on nitrogen-limited ecosystems (Holland et al. 1997). Some ecosystems are currently nitrogen-saturated, and more ecosystems will become nitrogensaturated as deposition continues. In these systems, additional nitrogen inputs will increase nitrogen pollution of surface and ground waters, lead to loss of nutrient cations such as calcium 
(McLaughlin et al. 1998), and possibly alter biodiversity without enhancing productivity. Because the nitrogen cycle is closely linked to the carbon cycle, the responses to nitrogen deposition should be considered in relation to increasing $\mathrm{CO}_{2}$ (Norby 1998), but the nature and importance of the questions will vary in different ecosystems.

\subsubsection{Ozone}

The negative influence of tropospheric ozone on terrestrial plants is undeniable, but the ultimate long-term impact for terrestrial ecosystems is likely to be much less than from $\mathrm{CO}_{2}$ and warming because of the seasonal nature of ozone presence and impact. In ecosystems dominated by deciduous trees the impact of tropospheric ozone is driven by cumulative impacts on foliage (Hanson et al. 1994; Kelly et al. 1995), with the greatest impact being reached only late in each growing season. Ozone impacts have the potential to be more cumulative in evergreen forests, where growth can be affected by increasing sensitivity to moisture stress at rather low ozone levels as well as by reduced carbohydrate production (McLaughlin and Downing 1996). If elevated $\mathrm{CO}_{2}$ reduces stomatal conductance, the impact of ozone should be partially mitigated. However, nitrogen oxide emissions are projected to increase in the next few decades, with the result that regional ozone problems may be exacerbated (Chameides et al. 1994) in a future climate, particularly a warmer one. Notwithstanding these general comments regarding the impact of tropospheric ozone, some species or genotypes do exhibit extraordinary sensitivity to tropospheric ozone and studies to understand such impacts and their implication for ecosystem diversity may be warranted.

\subsubsection{Other Factors}

The interacting effects of global change drivers may alter the frequency and intensity of relatively rare events, such as fires, insect or pathogen outbreaks, and the invasion and spread of exotic species. These phenomena occur primarily at the scale of large landscapes or regions, which is larger than the scale of the experiments proposed here. Whereas these phenomena are not suitable for experimental manipulation in the program proposed here, many of the ecosystem responses (dependent variables) in the proposed experiments will provide information directly relevant to predicting the probability of these events (e.g., fuel load and moisture content).

Recent declines in stratospheric ozone have led to concern about the adverse effects of increased ultraviolet-B (UV-B) radiation to human health. Plants are locally adapted to the local ambient UV-B, which varies widely with latitude and elevation, and there is no persuasive evidence that increases in UV-B will have important effects on terrestrial ecosystems. It should not be a high-priority issue for this research program.

\subsection{TREATMENT LEVELS}

How each global change driver is incorporated into an experiment will depend on the uncertainties, policy issues, and tractability of each specific ecosystem. In most cases, the levels of treatment should reflect either the current (or potential) range of a factor or a likely future state (say 50 to 100 years from now). This is relatively straightforward for atmospheric $\mathrm{CO}_{2}$ but can be more difficult for other drivers. 
A warming treatment could be represented as simply a constant increase from current diurnal and seasonal temperature patterns. Alternatively, only nighttime temperature could be increased, consistent with recent observations (Karl et al. 1984) and model predictions. Temperature extremes may be much more important factors to incorporate in experimental designs than changes in average temperature. Manipulation of temperature in an ecosystem will necessarily alter moisture, and the manner that this is done must be an important consideration.

Of the relatively few temperature-manipulation studies that have been conducted, most have altered only soil temperature. Consequently, many of the experimental design issues for whole-ecosystem warming have not been thoroughly explored by the research community. Similar questions also apply to the incorporation of altered precipitation into an experimental design:

Should the average amount of precipitation be changed or the periodicity of precipitation? We do not make specific recommendations here, except that the convening of planning workshops within the experimental and modeling research communities should be an important part of experimental design.

The temporal pattern of the treatment in relation to the length of the experiment must also be considered. The benefits and drawbacks of "square wave" treatments vs ramped treatments have been thoroughly debated, particularly with regard to elevated $\mathrm{CO}_{2}$. The imposition of a sudden, large increase in $\mathrm{CO}_{2}$ concentration can create a strong artifact, but very gradual increases may preclude determining responses to future levels within a useful time frame. In any case, there must be a clear recognition of the importance or pretreatment conditions on response, especially in the first year or two after treatments begin. Experiments must last long enough (at least 10 years) to minimize the influence of pretreatment conditions, as well as to incorporate the influence of year-to-year variation in climate (e.g., Owensby 1993).

An important consideration in planning experimental design and treatment levels is that it is impossible to create the future state of the environment within an experiment (e.g., seeds and soil used in an experiment today will not have developed under the increased $\mathrm{CO}_{2}$ concentration of the future). The intent should not be to create or represent the ecosystem of the future but to create repeatable and unambiguous experimental systems for testing the ability of models, based on our best understanding of processes, to correctly predict critical ecosystem responses to changes in the major climate change driving variables.

\subsection{PRIORITIZATION OF CRITICAL PROCESSES}

Experimental scales, treatment levels, and process-level measurements must be designed to fill critical gaps in our understanding of processes that are important in all ecosystems, as well as processes that may be specific to the high-priority ecosystems under study. While many ecosystem processes are well-understood, at least in some systems, major uncertainties remain in our understanding of critical processes, particularly at the larger spatial scales of mature trees and heterogeneous landscapes.

The capability to quantitatively balance the cycles (budgets) for carbon, water, and major nutrients is of particular importance for testing our understanding of these process-level interactions, as well as for quantifying the exchange of materials between the atmosphere and terrestrial ecosystems. A major challenge is to achieve quantitative closure in these cycles at the relatively large spatial and temporal scales critical to ecosystem processes and policy decisions (Landsberg et al. 1991; Ford and Teskey 1991). 
The greatest process-level uncertainties involve the effects of multiple, interacting environmental drivers on the metabolic, developmental, biogeochemical, and ecological processes through which autotrophs and heterotrophs interact to determine the assimilation and retention of atmospheric carbon. Eliminating these uncertainties will require careful experimental research that addresses processes occurring at multiple spatiotemporal scales and levels of biological organization.

\subsection{PRIORITIZATION OF CRITICAL ECOSYSTEMS}

Which ecosystems need to be studied? A global change study in virtually any ecosystem can be rationalized in some manner, so the real question is which ecosystems are of the highest priority for policy decisions. Prioritization will depend on the primary issue of interest (e.g., carbon sequestration, economic benefit, biodiversity) as discussed in the next section. Some ecosystems (those with short-lived or low-stature vegetation) are easier to study than others (e.g., forests), but tractability should not be a primary factor for prioritization. If tall forests are deemed to be of high priority based on biological or policy factors, then they must be studied regardless of the fact that grassland or agricultural studies will be easier and cheaper. Alternative approaches that attempt to resolve these practical constraints include the use of artificial or model ecosystems (e.g., Field et al. 1996).

In general, model ecosystems are selected for the relatively small stature of the dominant plants. Such ecosystems may be more easily or precisely studied than ecosystems with large plants. However, the environmental conditions that produce the short-statured plants of model ecosystems also impose constraints on extrapolating the responses of model ecosystems to other ecosystems that do not have the same limitations. A low-productivity system is not a model for a highproductivity system. A nonwoody system is not a model of a woody system. A water-limited system is not a model of a moist system. A recently disturbed system probably is not a model of a mature system.

Although the concept of a "model" ecosystem may be of limited utility for ecosystem-scale experiments, the use of model or typical plants may be more valuable in multifactorial experiments that focus on the component processes of ecosystems. Because the dominant plant species in a given ecosystem may change in response to environmental change, a range of plant functional types should be included in all experiments: For example, C3 compared to C4 compared to CAM (crassulacean acid metabolism) photosynthetic pathways; long-lived woody plants vs annual herbaceous plants; cold-deciduous compared with drought-deciduous compared with evergreen plants; plants reproducing by seed compared with those spreading vegetatively. Just as the full range of potential environmental conditions must be covered in ecosystem experiments, the full range of potentially important plant species must also be included.

We advocate a research program based on representative "major ecosystems" that are selected on the basis of their importance for the global carbon cycle, for food or fiber production, or for some other high priority of human societies. There are a number of factors that must be considered in prioritizing ecosystems for research. For example, ecosystems that presently store large amounts of living or dead organic carbon are potentially large sources of $\mathrm{CO}_{2}$ in a warmer environment (with a potential positive feedback on $\mathrm{CO}_{2}$ increase and warming) (Post et al. 1982; Olson et al. 1983; Parton et al. 1987; Pastor and Post 1988). Ecosystems that cover large areas and have high productivity globally are potentially important sinks for additional $\mathrm{CO}_{2}$ ( with a negative feedback on $\mathrm{CO}_{2}$ increase). The productivity of ecosystems that are limited by water can 
potentially benefit from increasing $\mathrm{CO}_{2}$ through enhanced water-use efficiency. Ecosystems that produce food and fiber for human use (directly or indirectly) are clearly important, and within those ecosystems, ranks of importance are related to the amount of food or fiber produced. Other criteria can also be used to evaluate the importance of different ecosystems, including ecosystem services to humans (Costanza et al. 1997), beauty, recreation, nostalgia, biodiversity, and rarity (for examples of alternative criteria, see Table 1). Whole-ecosystem experiments must be conducted in these high-priority ecosystems, in conjunction with multifactorial mechanistic studies of processes on smaller plots (e.g., constructed ecosystems designed to represent the major properties and processes of the high-priority ecosystems).

Table 1. Examples of terrestrial ecosystem prioritizations based on alternative criteria

\begin{tabular}{lcccc}
\hline \multicolumn{1}{c}{ Ecosystem type } & Total carbon & $\begin{array}{c}\text { Human } \\
\text { population }\end{array}$ & Biodiversity & $\begin{array}{c}\text { Ecosystem } \\
\text { services }\end{array}$ \\
\hline Forest, tropical wet & 2 & 9 & 1 & 6 \\
Forest, tropical dry & 12 & 5 & 3 & 5 \\
Forest, temperate & 6 & 3 & 8 & 3 \\
Forest, boreal & 8 & 10 & 11 & 10 \\
Woodland, temperate & 11 & 6 & 9 & 8 \\
Chaparral & 13 & 11 & 2 & 11 \\
Savanna, tropical & 3 & 4 & 6 & 7 \\
Grassland, temperate & 4 & 7 & 7 & 4 \\
Tundra, arctic and alpine & 9 & 14 & 13 & 14 \\
Peatland, boreal & 1 & 13 & 14 & 13 \\
Desert and semidesert, scrub & 7 & 12 & 10 & 12 \\
Desert, extreme & 15 & 15 & 15 & 15 \\
Wetland, freshwater & 5 & 8 & 5 & 1 \\
Wetland, coastal & 14 & 1 & 4 & 2 \\
Cultivated and cropland & 10 & 2 & 12 & 9 \\
\hline
\end{tabular}




\section{RECOMMENDED HIGH-PRIORITY BIOMES AND EXPERIMENTAL TREATMENTS}

Rational allocation of scientific resources requires prioritization of critical ecosystem types for major experimental effort. We propose two primary criteria: (1) Potential negative impacts of climate change on environmental resources and ecosystem services (NPP, harvestable productivity, biodiversity, water resources, etc.) and (2) potential to have major positive or negative effects on the concentration of atmospheric $\mathrm{CO}_{2}$ (Tables 1 and 2).

We identify five critical ecosystem types as highest priority for large-scale ecosystem experiments. In all cases, whole-ecosystem experiments are needed to test the ability of models to predict responses to interacting environmental drivers in the context of the spatial and temporal heterogeneity of landscapes in which these ecosystems are found. The primary variables for the large-scale experiments will always include elevated $\mathrm{CO}_{2}$, but the major interacting variables will vary from one ecosystem to another (e.g., increased warming is not likely to be a critical factor for tropical grasslands). In addition to the large-scale experiments, each ecosystem type should also have some multifactorial experiments (with an appropriate range of levels of each major factor) that include $\mathrm{CO}_{2}$, warming, water, nutrients, and, where relevant, air pollutants.

The size of each treatment plot in the multifactorial experiments will vary from one ecosystem type to another but must be sufficiently large to contain all major ecosystem components, including all plants as well as animals up to the size of small mammals. In some systems, grazing, or other relevant management practices, should be included as treatments in both the whole-ecosystem and the multifactorial experiments.

\subsection{HIGH-LATITUDE TUNDRA, TAIGA, AND PEATLANDS}

Warming is expected to be greatest in high northern latitudes. A global incremental increase in $\mathrm{CO}_{2}$ will be accompanied by a greater than average increase in temperature for these northern ecosystems. These ecosystems are important because they contain an amount of carbon in soil organic matter that may be about equal to the total carbon content of the present atmosphere, and a large fraction of this stored carbon could potentially be released to the atmosphere in a short time. Decomposition may be accelerated by warming itself and/or drying of soils and organic matter accumulations. On the other hand, stimulation of plant growth by elevated $\mathrm{CO}_{2}$ is probably strongly limited at cold temperatures. Thus, the potential exists for rapid losses of presently stored carbon, with little potential for additional carbon storage as a result of increasing $\mathrm{CO}_{2}$.

The primary treatments for the whole-ecosystem experiments should be elevated $\mathrm{CO}_{2}$ in combination with warming. Although the plants are generally small, treatment areas should be large enough to include small-scale heterogeneity, and the experiments should be replicated sufficiently to account for important aspects of large-scale heterogeneity (e.g., upland and lowland locations). Moist and wet tundras, especially with permafrost, are the highest priority systems for experiments. 


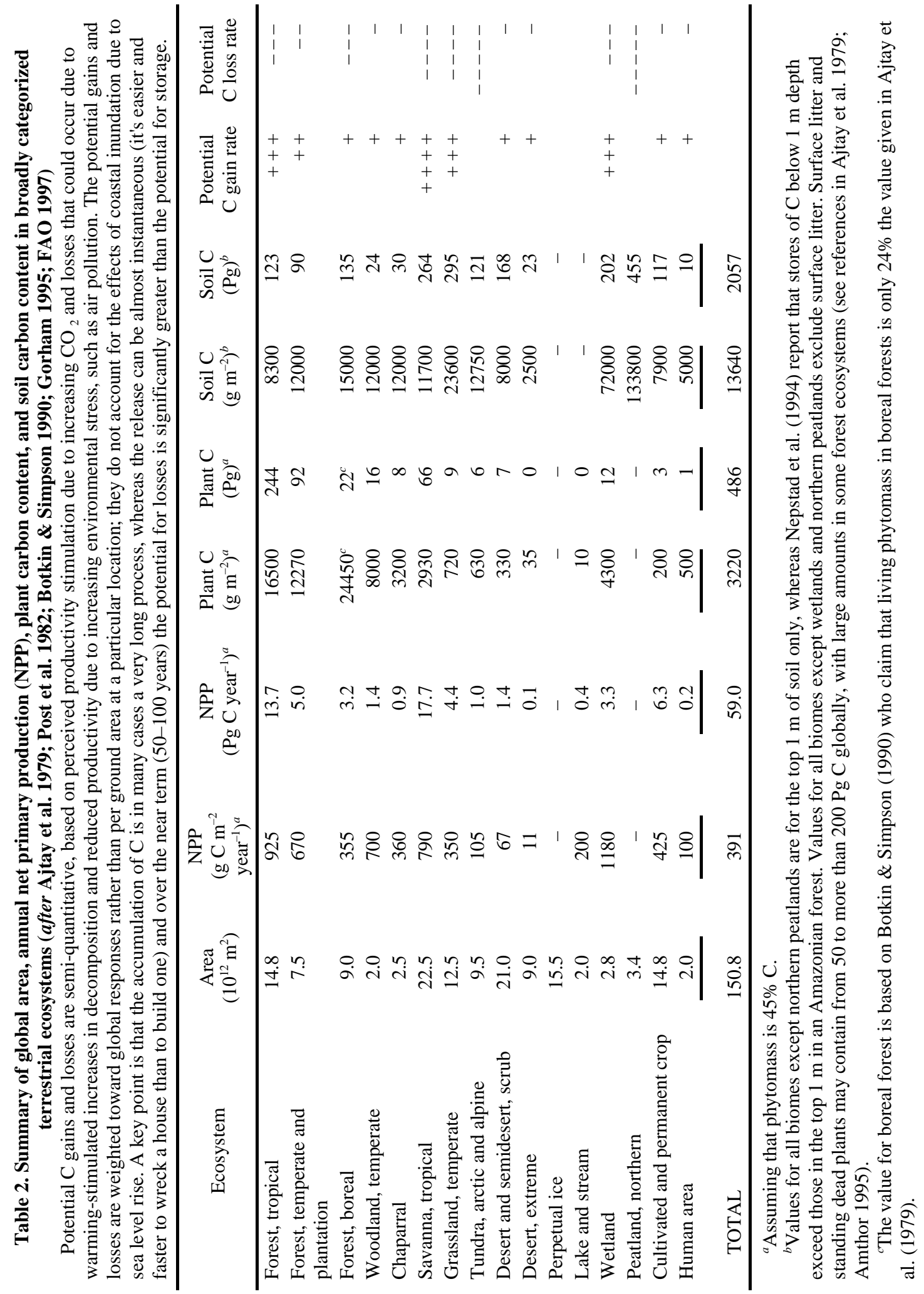


Several key hypotheses should be addressed by the ecosystem-scale manipulations, including:

A. Warming of northern ecosystems that now contain large amounts of soil organic matter, including surface peat, will result in the rapid decomposition of a significant fraction of that stored carbon (either as a result of warming itself, drying resulting from altered hydrologic regimes, or a combination of the two).

B. Loss of soil organic matter will greatly alter the hydrologic dynamics of the landscape, reducing water storage and perhaps even limiting NPP in some areas.

C. Annual NPP, which is now limited, will be stimulated by elevated $\mathrm{CO}_{2}$ and enhanced even further with warming. Part of the stimulation of NPP will be the result of a longer growing season, although this will be accompanied by a lengthening of the most active period of heterotrophic metabolism.

D. Changes in growth phenology and in the timing, form, and amount of NPP during the brief arctic growing season could negatively affect the reproductive success of migratory bird species that breed in high-latitude tundra and wetlands.

E. Photosynthetic stimulation by elevated $\mathrm{CO}_{2}$ will not be sustained in these sink-limited systems. There is no evidence that decomposition rate will acclimate to changing environmental conditions. The dynamics under a warmer, and at least for upland sites, drier environment will result in long-term loss of carbon to the atmosphere.

F. Plant species composition will shift toward more woody vegetation. This is likely to alter plant community structure and diversity and could have a negative impact on resident animal species adapted to current vegetation structure.

\subsection{SEMIARID GRASSLANDS AND RANGELANDS}

Semiarid grasslands (including short-grass prairie) and shrub ecosystems are extremely vulnerable to both direct human impacts and the effects of climatic variability. Such ecosystems are important globally, both as potentially valuable grazing lands as well as reservoirs of biodiversity. The western United States contains a large area of such ecosystems, which are currently under threat from a variety of stresses, including overgrazing, water diversions, invasions of exotic species, suburbanization, and nitrogen deposition.

Such ecosystems often contain a mix of $\mathrm{C} 3$ and $\mathrm{C} 4$ grasses, herbs, and shrubs that can change dramatically in response to climate shifts or changes in land management. Increasing $\mathrm{CO}_{2}$ could potentially increase NPP by stimulating photosynthesis (mainly in the C3 component) and by increasing water use efficiency (both $\mathrm{C} 3$ and $\mathrm{C} 4$ ). Major changes in belowground carbon allocation are possible, and potentially important for soil carbon pools.

The primary treatments for catchment-scale ecosystem experiments should be elevated $\mathrm{CO}_{2}$ in combination with increased and decreased precipitation. Treatment areas must be large enough to compensate for small-scale heterogeneity, as well as the potential increase in woody vegetation.

Several key hypotheses should be addressed by the ecosystem-scale manipulations, including: 
A. Alterations in the timing and amount of precipitation in semiarid rangelands will have a major impact on the structure, productivity, and species composition of local vegetation and will also alter the relative proportions of short-grass steppe, shrub-steppe, and semidesert across large regions. Changes in precipitation will also have a strong effect on the condition, structure, and biodiversity of riparian communities.

B. Increasing $\mathrm{CO}_{2}$ may enhance NPP by a combination of stimulated photosynthesis and increased water-use efficiency, if the ratio of precipitation to evapotranspiration remains the same or increases.

C. Increasing $\mathrm{CO}_{2}$ will enhance allocation of carbon below ground, but $\mathrm{CO}_{2}$ if combined with increased soil moisture will result in greater heterotrophic activity and reduce soil carbon stores.

D. $\mathrm{C} 3$ plants will benefit disproportionally from $\mathrm{CO}_{2}$ increase, but warming will rebalance the difference in the $\mathrm{C} 3$ and $\mathrm{C} 4$ responses to $\mathrm{CO}_{2}$.

E. Both plant and animal abundance and diversity will respond strongly to changes in NPP. In these systems, increases in NPP should increase the diversity of both plants and animals, whereas decreases in NPP will have strong negative effects on secondary production and animal diversity.

F. $\quad \mathrm{CO}_{2}$-stimulated increases in NPP will not result in increased nutrient limitation. Increased decomposition rates as a result of higher soil moisture may also provide additional nutrients to further enhance growth.

\subsection{TROPICAL FORESTS}

Because of their large areal extent, tropical forests have the potential for large global gains or losses in carbon storage, both in plants and soil. The distributions, and perhaps relative proportions, of seasonal vs evergreen forests are likely to change with potential global changes.

Whereas tropical forest ecosystems are generally considered to be nutrient limited, especially with regard to available phosphorus, the response of these ecosystems to rising $\mathrm{CO}_{2}$ concentrations may be strong where other limitations are not extreme. Temperatures will not increase significantly in these regions with projected global warming, but the already high temperatures should enhance responses to $\mathrm{CO}_{2}$. Effects of altered water availability could be significant on plant growth phenology, as well as decomposition processes. The primary treatments in the catchment-scale experiments should be elevated $\mathrm{CO}_{2}$ in combination with increased and decreased precipitation. Both the large-scale ecosystem experiments and the multifactorial experiments will need to be large because of the stature of the vegetation. Treatment areas must be large enough to capture ecosystem-scale processes, including species interactions (i.e., areas many times the crown diameter of canopy trees). 
Key hypotheses include the following:

A. Increasing $\mathrm{CO}_{2}$ will enhance NPP by stimulating photosynthesis and increasing belowground carbon allocation, which may help alleviate some of the nutrient limitation on NPP.

B. Increased water use efficiency should increase water yield for both wet and dry forests and reduce the effects of dry-season water stress.

C. Reduced precipitation will expand seasonal forests and contract evergreen forests, reducing regional productivity, resulting in increased fire frequency, reducing carbon storage in trees, and causing increased extinction rates among endemic plant and animal species around the periphery of wet forest areas.

D. Changes in the seasonality and interannual variability of precipitation and NPP will have major effects on animal populations and the overall biodiversity of higher trophic levels. Increased variability will decrease animal diversity but have relatively little effect on plant diversity.

E. Increases in NPP, if seasonal and interannual variability remain unchanged or decrease, should have a positive effect on the population viability of both plants and animals and should increase overall biodiversity.

F. Increased carbon input to soil, if combined with drier soil conditions that reduce decomposition, will increase overall carbon sequestration in soil.

\subsection{TEMPERATE FORESTS}

Temperate forests serve many critical economic and social functions. $\mathrm{As}^{\mathrm{CO}_{2}}$ concentrations increase, most temperate forest regions are likely to experience moderate warming, with potentially significant changes in the amount and seasonality of precipitation. Some will also experience increases in air pollution and nitrogen deposition. Whereas the $\mathrm{CO}_{2}$ increase will generally stimulate production, many of the associated environmental changes may limit production. In both evergreen and deciduous forests, warming may increase the growing season length, tending to enhance annual NPP. On the other hand, warming will also stimulate heterotrophic metabolism. In terms of whole-ecosystem carbon balance, these two processes operate in opposite directions. In addition, warming may result in drying (depending on changes in precipitation, if any), possibly increasing the incidence of water stress. Increasing $\mathrm{CO}_{2}$ might mitigate this, however, because of its effects on water-use efficiency.

The primary treatments for the whole-ecosystem manipulations should be elevated $\mathrm{CO}_{2}$ in combination with regionally appropriate warming (and possibly precipitation changes). In addition to $\mathrm{CO}_{2}$, warming, precipitation, and nutrients, the multifactorial experiments may need to include ozone increase to cover the full range of future conditions in some regions. Treatment areas must be large enough to capture ecosystem-scale processes, including species interactions (e.g, at least 5 ha for whole ecosystem experiments and up to a hectare for the multifactorial experiments). Both deciduous and evergreen communities should be studied. 
Several key hypotheses should be addressed by the ecosystem-scale manipulations, including:

A. The combination of elevated $\mathrm{CO}_{2}$ and warming will result in enhanced annual NPP and enhanced heterotrophic metabolism, with consequently little change in annual NEP.

B. Enhanced NPP with elevated $\mathrm{CO}_{2}$ in combination with warming will result from stimulated photosynthetic rates in all forests and from a combination of stimulated photosynthesis and changes in leaf phenology and function that extend the period of active photosynthesis in forests limited by winter temperature. On the other hand, warmer summers will increase high-temperature stress, reducing midsummer photosynthesis and tree growth.

C. Photosynthesis will not acclimate to elevated $\mathrm{CO}_{2}$; plant respiration will acclimate to warming, and decomposition will not acclimate to warming. As a result, biomass and soil organic matter inputs will increase, whereas soil organic matter stock may remain the same or decrease. Associated changes in nutrient turnover and availability may accentuate these changes.

D. In polluted areas, increased air pollution, namely ozone, will limit the effects of increasing $\mathrm{CO}_{2}$ on photosynthesis and tree growth.

E. Warming will increase the incidence of water stress, which will be moderated by elevated $\mathrm{CO}_{2}$ (as a result of increased water-use efficiency).

F. Elevated $\mathrm{CO}_{2}$ in combination with warming will increase photosynthate allocation to roots and the cycling of carbon through roots to the soil, and then the atmosphere will be accelerated.

G. Warming (and/or drying) will increase mortality near the warmer (and/or drier) edges of species ranges, leading to changes in species composition.

\subsection{MAJOR FOOD CROPS (WHEAT, RICE, AND MAIZE)}

Most of the highly productive grasslands, forests, and wetlands in the United States (and globally) have been converted to agricultural uses. The potentially strong effects of increased $\mathrm{CO}_{2}$ and warming on crop productivity may not be realized because crop productivity is already under

strong control by farm management and crop breeding. Crop breeding and management (including increased energy and fertilizer inputs) have produced the remarkable yield gains achieved in the past 50 years. The actual additional gains in yield caused by $\mathrm{CO}_{2}$-fertilization may be relatively small.

The major issue is whether the negative effects of increased temperature and potential evapotranspiration on yield in the major grain crops can be mitigated by $\mathrm{CO}_{2}$-stimulated increases in water-use efficiency and photosynthesis.

Primary treatments for the field-scale ecosystem experiments should be elevated $\mathrm{CO}_{2}$ in combination with warming (and in some cases air pollution).

Key hypotheses include the following: 
A. In the $\mathrm{C} 3$ crops (wheat, rice), growth will be stimulated by $\mathrm{CO}_{2}$ but limited by warming, with no net change in yield with $\mathrm{CO}_{2}$ increase in combination with warming. In $\mathrm{C} 4$ crops, $\mathrm{CO}_{2}$ will have little effect on yield, but warming will reduce yield.

B. Warming will change optimal sowing dates and the geographic distribution of crops. In the case of island countries, such as Philippines, some crops may be completely displaced.

C. In dry, rain-fed agriculture, increasing $\mathrm{CO}_{2}$ will increase yield through enhanced water-use efficiency.

D. In low-input (fertilization and irrigation) agriculture, $\mathrm{CO}_{2}$ will have modest effects in absolute terms, while in high-input areas the gains will be much greater.

E. C3 weeds will compete better with $\mathrm{C} 4$ crops, which will be an issue of increasing importance as levels of tillage are reduced. 


\section{IMPLEMENTATION AND QUANTIFICATION OF EXPERIMENTAL TREATMENTS AND RESPONSES}

Manipulating the environment at the whole-ecosystem scale presents engineering challenges beyond those typically encountered in ecological research. Existing technology, while useful at the scale of some systems of interest, is inadequate for manipulation of large-scale systems, such as tropical and temperate forests. In the discussion that follows, the focus will be primarily on whole-ecosystem manipulations. Current technology has been applied successfully for realistic treatments at the scale that would be useful for the process-level studies (e.g., very large open-top chambers) so will not be discussed in detail here. However, innovative exposure systems for manipulating atmospheric $\mathrm{CO}_{2}$ concentrations, water, and temperature at larger scales will need to be developed.

Ideally, exposure systems should have minimal impact on the experimental area and introduce no artifacts. For example, the continuous forced air used in existing free-air $\mathrm{CO}_{2}$ exposure (FACE) systems may alter frost patterns at the beginning and end of the growing season. It will usually be necessary to include both a completely unmanipulated control and a control with the treatment infrastructure but no treatment.

Another important consideration is that manipulation of one environmental factor will often result in uncontrollable changes in other factors. For example, enclosures to control atmospheric $\mathrm{CO}_{2}$ may cause warming, atmospheric warming changes evapotranspiration rates, throughfall exclusion reduces nutrient input to the system as well as reducing water, and elevated $\mathrm{CO}_{2}$ may alter soil water content through its effect on water use efficiency (Owensby et al. 1993). In addition to full monitoring of the spatial and temporal variation in the experimental variables, it is critical to also quantify the levels of other physical conditions that may be directly or indirectly affected by the primary experimental factors. Even in "controlled" experiments, all major driving variables must be thoroughly monitored to avoid confounding effects that can lead to misinterpretation of experimental results (Huston 1997).

Finally, it is important to tailor the treatments to the system under study-not all systems will require manipulation of all climatic factors. Temperature manipulations, for example, may be unnecessary in tropical forest systems. Some treatments, such as nutrient additions or use of extreme treatment levels, may be appropriate for mechanistic studies for multifactorial experiments but would not be necessary at the whole-ecosystem level. An exception to this might be introduction of nitrogen or other anions through acidic precipitation in large-scale experiments in systems predicted to experience these conditions in the future.

\subsection{EXPERIMENTAL TREATMENTS}

\subsection{1 $\mathrm{CO}_{2}$ Enrichment}

$\mathrm{CO}_{2}$ enrichment will be necessary for all systems under study, because it is the only ubiquitous and uniform climate change factor and because of its potential to interact with all other factors of interest. Current designs, such as FACE (Hendrey and Kimball 1990) or open-top chambers, are appropriate for the maximum size of the multifactor experiments recommended, but they are not presently suitable for exposing catchment-sized areas without modification. Regardless of the $\mathrm{CO}_{2}$ injection protocol (e.g., constant injection or control to a preselected set point), the 
major technological challenge associated with enrichment will be to ensure adequate horizontal and vertical mixing of the gas across a large area. Selection of a scenario for testing the large-scale experiments will have to include such considerations as 24-hour vs daytime enrichment, year-round vs seasonal enrichment, and enrichment of canopy vs full vertical profile.

\subsubsection{Warming}

Warming of the atmosphere may prove to be the greatest challenge to the engineers and scientists involved in the whole-ecosystem studies. Like precipitation manipulations, warming can be achieved actively, by adding heat to the air, or passively, through reducing radiative cooling or by use of solar heating techniques. Active temperature manipulation has been used, in conjunction with $\mathrm{CO}_{2}$ enrichment, in open-topped chamber studies (Norby et al. 1997) and through use of infrared radiators above the canopy of a Colorado alpine meadow (Harte et al. 1995). Passive heating has not been employed at other than relatively small scales, for example, in the use of plastic open-topped chambers on the tundra (Henry and Molau 1995). Passive nighttime warming at the stand level has been proposed, however, using a retractable curtain designed to retard heat loss at night (Luxmoore et al. in press).

Although atmospheric temperature has not yet been manipulated at large scales, soil temperature has been increased in several studies through the use of buried or surface warming cables (McHale and Mitchell 1996; Peterjohn et al. 1993). Although heating the soil gives information on temperature effects on soil processes, such as nutrient cycling, it fails to account for indirect effects of atmospheric warming. Indirect (i.e., plant-mediated) effects of atmospheric warming on soil processes may be more dramatic than direct effects. Therefore, whereas soil warming alone may be useful in mechanistic studies, it does not allow for realistic soil temperature dynamics.

\subsubsection{Water}

Precipitation manipulation has been achieved to date through two general approaches, alone or in combination: Passive manipulation involving interception and removal of ambient precipitation, either above or below the canopy level, and active manipulation, where natural rainfall is replaced or supplemented by rainfall of altered chemistry or volume (Hanson et al. 1994, 1998). Both approaches have been used at the scale of large plots to ecosystems. In the largest field manipulation attempt to date (the $12,800 \mathrm{~m}^{2}$ Throughfall Displacement Experiment in the Oak Ridge National Environmental Research Park), incoming precipitation on a "dry" plot is intercepted by a trough system below the canopy level and passively transported across an "ambient" treatment plot and redistributed across a "wet" treatment plot (Hanson et al. 1994). A combination of passive and active control has also been achieved through complete interception of rainfall by a 7000- $\mathrm{m}^{2}$ plastic roof placed under the canopy of a Norway spruce forest on the coast of Sweden (Moldan et al. 1995). In this case, rainfall simulating pre-industrial deposition chemistry was applied through a sprinkler system designed to mimic naturally occurring rain-event frequency and duration. In both experiments, steps were taken to reduce confounding of results by rainfall exclusion devices. Irrigation, highly developed for use in agroecosystems, is another form of active manipulation that could be used to simulate increased precipitation in unmanaged systems as well. As discussed in section 4, consideration should be given during the planning stages to the possibility of changes in the seasonality of rainfall events not only to the total volume of precipitation. Drought occurring early in the growing season, even of short duration, could have 
consequences for an ecosystem that might not be manifested through year-round and constant reductions in precipitation input.

\subsection{VERIFICATION OF TREATMENT AND QUANTIFICATION OF RESPONSES}

\subsubsection{Data Collection and Management}

Detailed data should be collected throughout the life of a site that verify that treatment is being achieved to a specified level of precision and fully quantify all major response variables and all potential driving variables (including those not directly manipulated in the experiment). In both the multifactorial experiments and the large-scale experiments, it is essential that intermediate "process level" variables (e.g., nitrification rates, soil microinvertebrate population sizes) be measured in addition to the primary "response variables" (e.g., net ecosystem productivity, species diversity). Measurement of these intermediate variables is essential for testing mechanistic hypotheses about the regulation of the primary responses, as well as for demonstrating cause-andeffect relationships between the independent and dependent variables. All sampling should be conducted at a scale and spatial resolution appropriate to both the treatment and the levels of spatial and temporal heterogeneity that exist in the ecosystem being manipulated.

All experimental sites should collect sufficient data on weather, atmospheric inputs and chemistry, soil conditions, pests, pathogens, and other disturbances to detect environmental changes resulting either from technological artifacts, from confounding unintentional effects of the manipulation, or from other factors not directly controlled in the experiment. Meteorological information is critical to interpreting results and making predictions based on model output as well as to making cross-site and cross-system comparisons. A list of recommended physical measurements would include (but is not necessarily limited to) the following: Precipitation input, irradiance, photosynthetic photon flux density (PPFD), air temperature, soil temperature, and moisture at multiple depths including surface measurements, atmospheric ozone concentration, and relative humidity.

To maximize the usefulness of information resulting from large-scale manipulations of differing systems, some degree of standardization is required. A minimum suite of measurements of dependent variables to document ecosystem response should be required at each site (with funds specifically allocated for such measurements). To the extent possible, common protocols for these measurements should be agreed upon. Among this minimum suite should be ecosystem-level measurements of NPP, plant growth rates, fine root turnover, soil carbon content, phenology, and soil nitrogen.

Finally, a major strength of the national program presented here is the opportunity for synthesis of large-scale experimental results across several ecosystem types and across diverse environmental conditions. To that end, provisions should be made to enter and archive data in a central facility. Formats for entering data (as well as software used) should be agreed upon and common to all sites. These databases should be accessible for use by other investigators (with some procedure in place to allow original investigators first rights of interpretation and publication within a reasonable length of time). The Carbon Dioxide Information and Analysis Center (CDIAC) at Oak Ridge National Laboratory serves as a model of the type of central facility that will be required.

\subsubsection{Complete Flux Accounting}


Much of the uncertainty about the magnitude of terrestrial ecosystem impacts on the global carbon cycle result from our inability to achieve mass balance, even at scales as small as an individual tree. Technologies to achieve quantitative closure of the carbon, water, and nutrient cycles are available and attempts to estimate the effects of elevated $\mathrm{CO}_{2}$ on daily and annual net ecosystem exchange of carbon and water vapor have yielded useful results (Körner and Arnone 1992; Overdieck and Forstreuter 1994; Ham et al. 1995; Arnone and Körner 1995; Bremer et al. 1996; Field et al. 1996; Hattenschwiler and Körner 1997; Owensby et al. 1993). Canopy transpiration is often reduced at elevated $\mathrm{CO}_{2}$ (Owensby et al. 1993), although whole-plant and/or community water use may increase as a result of the greater leaf area of $\mathrm{CO}_{2}$-enriched plants (Schapendonk et al. 1997). Annual estimates of carbon balance have, by comparison, been complicated by an inability to document both the aboveground and belowground fluxes of carbon. For example, Wang et al. (1998) used gas exchange data collected from young birch trees which indicate that only about half of the enhanced photosynthetic production at elevated $\mathrm{CO}_{2}$ was realized in growth. The other half was presumably lost to the increased production of fine-root and symbiotic mycorrhizas and other belowground processes. Until we are able to quantify all major fluxes, it will be difficult to determine the relative contributions of various carbon-cycle processes under the range of relevant conditions.

\subsubsection{Development of Belowground Instrumentation}

Responses of belowground processes are important but poorly known in all systems and with all treatments. Belowground studies are currently limited by methodology and confounded by spatial and temporal heterogeneity and by the small scales at which processes of great importance to the ecosystem operate. With a few exceptions, existing techniques are destructive, labor-intensive, and do not adequately capture the temporal and spatial dynamics of the system under study. Technology exists that would increase our ability to monitor and measure many belowground processes nondestructively and with minimal disturbance, but specific instruments and methodology need to be developed. Funds must be committed to support not only the development of systems for large-scale delivery of treatments, but also for nondestructive, noninvasive, real-time monitoring equipment for use belowground. The use of state-of-the-art instrumentation may also dictate the further development of advanced statistics and theory to deal with large amounts of covarying data.

Increased attention should be paid to understanding belowground diversity, the functional roles played by members of the belowground community, and their sensitivity to climatic change. Ecosystems may not only be sensitive to changes in diversity (especially loss of particular functional groups) but may also be constrained in their movement across a landscape by the rates of movement of critical soil organisms. There is presently no way to examine the dynamics of belowground communities in situ, although to some extent we can measure the consequences of change.

\subsubsection{New Model Structures and Capabilities}

Existing models of ecosystem dynamics have been developed under the severe constraints of limited information on the responses of major ecosystem components (e.g., the growth of mature trees) to the full range of environmental conditions experienced under current climatic conditions. The proposed experimental program will allow major improvements in models of ecosystem 
components as well as a better understanding of the interaction among major ecosystem components and processes.

A major challenge is the development of whole-system models that combine multiple processes and their interactions. These processes occur over a range of spatial and temporal scales, which provides major conceptual and computational challenges. Integration of the spatial and temporal heterogeneity in the driving variables for large landscapes will require the combination of physical and biological models into a "multi-model" that links models with different spatial and temporal scales.

Currently, testing ecosystem models is virtually impossible at any but the most simplistic qualitative levels. The primary benefit of the proposed large-scale experiments is that they will allow rigorous quantitive testing of ecosystem models under both current (control) and "possible future" (experimentally elevated $\mathrm{CO}_{2}$ and temperature) conditions.

Only with this combination of quantitative large-scale experiments and validated ecosystem models will it be possible to improve our estimates of future climatic conditions and the potential impacts of an altered climate on ecosystem processes critical to human well-being. 


\section{RELATIONSHIP TO EXISTING RESEARCH PROGRAMS}

The proposed program of integrated ecosystem experiments is complementary to ongoing research and monitoring programs within the U.S. Global Change Research Program (USGCRP) but does not replace them. Existing research and monitoring programs are addressing specific issues across a range of spatial and temporal scales, but none combine the process-level experimental research on responses to interacting factors with the large-scale model-validation experiments proposed here.

Intensive, large-scale "monitoring experiments," such as GEWEX (Global Energy and Water Cycle Experiment), BOREAS (Boreal Ecosystem-Atmosphere Study), and FIFE [First ISLSCP (International Satellite Land Surface Climatology Program)], are designed to quantify land-atmosphere exchanges of energy and materials over large areas for short time periods, but they do not address the mechanisms of interactions among ecosystem processes that determine the terrestrial response. Other global-change-related monitoring programs, such as the Ameriflux network of "eddy-flux-correlation" towers, serve the purpose of quantifying spatiotemporal variation in fluxes of $\mathrm{CO}_{2}$ and water vapor in "natural" terrestrial ecosystems but do not address the processes that cause those fluxes. Methods from all of these monitoring programs can contribute to better quantification of ecosystem responses in the proposed large-scale experiments.

A network of elevated- $\mathrm{CO}_{2}$ experiments is currently being developed that uses "free air" releases of $\mathrm{CO}_{2}$, called FACE (Free-Air $\mathrm{CO}_{2}$ Enrichment). The FACE research program in North America is supported primarily by the multiagency Terrestrial Ecology and Global Change program and by the U.S. Department of Energy's Terrestrial Carbon Processes Program. There are currently seven FACE facilities in the United States and one under construction in tropical forest in Panama. Other forest sites include a loblolly pine forest in North Carolina, a sweetgum forest in Tennessee, and a regenerating northern hardwood system in Wisconsin. A site in Minnesota is investigating biodiversity of grasses; the Nevada site is investigating desert ecology; and a chaparral system is under investigation in California. The Arizona FACE site has been exposing different agricultural systems to elevated $\mathrm{CO}_{2}$. The Rhinelander FACE, with a two-way factorial manipulation of $\mathrm{CO}_{2}$ and ozone, is an example how this type of experiment can address interacting factors.

The FACE technology provides a promising method for the large-scale ecosystems experiments proposed here, although existing FACE "rings" are much smaller (e.g., 30-m diameter) than those required for ecosystem-scale experiments. In addition, most of the existing FACE experiments are single-factor manipulations, with only $\mathrm{CO}_{2}$ being experimentally manipulated. The current series of FACE experiments are providing critical background information for the design of the program proposed in this report.

In a broader sense, the experimental ecosystem research program supports the priorities of the larger set of federal and nonfederal agencies responsible for the stewardship of the nation's public lands and their natural and managed ecosystems. The proposed experiments are relevant to understanding ecosystem responses to the range of factors (biological, chemical, and geophysical) that regulate, limit, or modify ecosystem structure or function.

Strategic management of our nation's resources in a sustainable manner will require new approaches in science and technology to address the issues of cumulative impacts of these multiple factors as a means of setting management, conservation, and restoration priorities. The rationale for the need for this research is outlined in a recent report from the President's Committee of Advisors on Science and Technology (PCAST). Key recommendations include (1) a need to 
augment the research on ecosystem effects in several areas to improve the scientific basis for documenting, predicting, and assessing the probable direct and indirect effects on ecosystems resulting from human-induced changes in climate and atmospheric composition, including climatic extremes, and on the interactive effects on ecosystems of elevated temperature and altered moisture availability, elevated UV-B levels, and elevated levels of carbon dioxide, (2) a need for research on how such changes will affect the sustainability, structure, and function of ecosystems in the context of other ongoing or projected environmental changes that could exacerbate or ameliorate the effects of climate change, with a particular need to develop a means of identifying which ecosystems are in need of priority study (PCAST 1998).

A recent review of the U.S. Global Change Research Program (USGCRP) by the National Research Council's Board on Sustainable Development and its Committee on Global Change Research further concluded with regard to ecosystem-level research that "(1) ecological and integrative manipulation experiments designed to address ecosystem responses to global change, including climate change, are supported by agencies largely on an ad hoc basis; (2) extending and integrating understanding of local ecosystem processes and responses from process-level studies to whole ecosystems and regional scales requires modeling which is less well developed than other modeling areas of global change research; (3) research on integrative ecosystem response modeling needs to be not only enhanced, but also more closely coordinated with ground- and space-based observational and experimental studies, and (4) the basic science to address the impacts of climate change on ecosystems and on water resources is currently inadequate."

The current federal agency programs that are most likely to benefit from the research approach for terrestrial ecosystems outlined in this strategy are summarized as follows (USGCRP 1997):

U.S. Department of Agriculture. The USDA's research program in global change focuses primarily on (1) the relationship between agriculture and forestry and the emissions and sinks of greenhouse gases and (2) how agricultural and forestry production, sustainability, and trade are likely to be affected by changes in this relationship. The USDA supports research on the effects of land-use change and management intensity on agricultural, range, and forest growth, structure, and carbon dynamics. Studies range in scale from the molecular to the ecosystem level.

U.S. Department of the Interior. To support DOI responsibilities for managing large areas of land, the DOI supports development of data resources on natural resource characterization and change detection related to land surface, land use, and land cover. The DOI also employs spaceand ground-based data in studies that provide a scientific basis for addressing such issues as desertification, wildland fires, and spread of noxious weeds in rangelands and national preserves.

National Aeronautics and Space Administration. NASA supports research to support analysis through development of observational tools and methods, process models, and data products that can be used to increase understanding and provide the basis for enhancing the production of food, fiber, and other renewable natural resources from a landscape while maintaining area for biodiversity, environmental quality, and climate protection. Current research includes process studies that assess the consequences of land-cover and land-use changes and losses for biogeochemical, hydrologic, and biophysical characteristics of a landscape, and development and validation of regional and global models of ecosystem processes and their interactions with hydrological and atmospheric systems.

U.S. Department of Energy. DOE supports programs in terrestrial carbon processes, and ecological research aimed at providing scientific knowledge of terrestrial components of the global carbon cycle. These activities, coupled with observations of atmospheric carbon dioxide changes, provide fundamental understanding of the biophysical processes needed for predicting the 
terrestrial sinks for future levels of atmospheric carbon dioxide. Experiments with crop and natural ecosystems are providing the empirical foundation for evaluating consequences of climate change and for assessing the effectiveness of carbon management and control strategies. Effects on ecosystems as the result of the cumulative influence of multiple factors, such as climate, carbon dioxide, nutrients, and atmospheric deposition, are evaluated in field experiments as well. The research is aimed at improved scientific understanding and prediction of the consequences of global environmental change.

U.S. Environmental Protection Agency. EPA supports ecological effects research to evaluate the response of terrestrial systems (primarily forests) to climate variability and change. Research is also focused on the development of indicator methods for detection of ecological effects of climate change.

National Science Foundation. NSF supports research to improve the description and understanding of the physical, biological, chemical, and human processes that result from changes in land use, land cover, global economic productivity, and resource sustainability. In terrestrial ecosystems, this research includes studies of the effects of land use on the biological and ecological diversity of managed and unmanaged ecosystems and the resulting effects of altered diversity on ecosystem processes.

The primary interagency program aimed at terrestrial ecosystems is the Terrestrial Ecology and Global Change (TECO) program. This program, with multiagency funding, focuses on exchanges of carbon and other trace gases as well as other cause-and-effect interactions between terrestrial ecosystems and other natural systems affected by global change.

Internationally, the Global Change Terrestrial Ecosystem (GCTE) program is a Core Project of the International Geosphere-Biosphere Programme (IGBP) and encourages research on biogeochemical cycling of carbon and nutrients within ecosystems with a focus on global change issues related to agriculture, forestry, and soils. 


\section{CONCLUSIONS}

A new approach to ecosystem research is needed to provide the information required to guide global change policy decision-making. Past, large-scale ecosystem research programs [e.g., the International Biological Program (IBP) of the 1960s and 1970s] were primarily descriptive rather than experimental, and most current experimental ecosystem research is at scales too small to address whole-ecosystem responses.

A program of intensive, large-scale ecosystem experiments is proposed that supports both the development and testing of the predictive ecosystem models needed to evaluate alternative policy responses to the highly uncertain future environment resulting from global change. Key features of the program are experiments that address responses to multiple interacting environmental factors (e.g., $\mathrm{CO}_{2}$, temperature, precipitation, nitrogen) and experiments at two spatial scales, one designed for development of process-level understanding and models and one for testing complex ecosystem models that combine multiple interacting processes. Another critical feature of the proposed experiments is that they must be both large-scale and long-term.

This program represents a major change in the way ecosystem research is conducted: From short-term, single-investigator-driven projects to long-term, multi-investigator, policy-driven research. The program will require a substantial increase in the funding for ecosystem research as well as an unprecedented level of coordination and cooperation among the large, interdisciplinary research teams that will be required for each set of experiments.

The program cannot succeed without a significant commitment to long-term funding for (1) maintaining experimental treatments; (2) collecting, analyzing, and archiving data;

(3) supporting the multiple disciplines required to address ecosystem processes; and (4) developing and testing simulation models in close coordination with experimental research, environmental monitoring, and remote sensing. 


\section{REFERENCES}

Amthor, J. S. 1995. Terrestrial higher-plant response to increasing atmospheric $\mathrm{CO}_{2}$ in relation to the global carbon cycle. Global Change Biol. 1:243-74.

Arnone, J. A., III, and C. Körner. 1995. Soil and biomass carbon pools in model communities of tropical plants under elevated $\mathrm{CO}_{2}$. Oecologia 104:61-71.

Ajtay, G. L., P. Ketner, and P. Duvigneeaud. 1979. Terrestrial primary production and phytomass. pp. 129-81. In B. Bolin, E. T. Degens, S. Kempe, and P. Ketner (eds.), The Global Carbon Cycle. Wiley, Chicester, U.K.

Bazzaz, F. A. 1990. The response of natural ecosystems to the rising global $\mathrm{CO}_{2}$ levels. Annu. Rev. Ecol. Syst. 21:167-96.

Botkin, D. B., and L. G. Simpson. 1990. Biomass of the North American boreal forest. Biogeochemistry 9:161-74.

Bremer, D. J., J. M. Ham, and C. E. Owensby. 1996. Effect of elevated atmospheric carbon dioxide and open-top chambers on transpiration in a tallgrass prairie. J. Environ. Qual. 25:691-701.

Bruno, M., and F. Joos. 1997. Terrestrial carbon storage during the past 200 years: A Monte Carlo analysis of $\mathrm{CO}_{2}$ data from ice core and atmospheric measurements. Global Biogeochem. Cycles 11:111-24.

Chameides, W. L., P. S. Kasibhatla, J. Yienger, and H. H. Levy II. 1994. Growth of continental-scale metro-agro-plexes, regional ozone production, and world food production. Science 264:74-77.

Costanza, R., R. d'Arge, R. de Groot, S. Farber, M. Grasso, B. Hannon, K. Limburg, S. Naeem, R. V. O’Neill, J. Paruelo, R. G. Raskin, P. Sutton, and M. van den Belt. 1997. The value of the world's ecosystem services and natural capital. Nature 387:253-60.

Curtis, P. S. 1996. A meta-analysis of leaf gas exchange and nitrogen in trees grown under elevated carbon dioxide. Plant Cell Environ. 19:127-37.

Curtis, P. S., B. G. Drake, P. W. Leadley, W. Arp, and D. Whigham. 1989. Growth and senescence of plant communities exposed to elevated $\mathrm{CO}_{2}$ concentrations on an estuarine marsh. Oecologia 78:20-26.

Curtis , P. S., and X. Wang. 1998. A meta-analysis of elevated $\mathrm{CO}_{2}$ effects on woody plant mass, form, and physiology. Oecologia 113:299-313.

Easterling, D. R., B. Horton, P. D. Jones, T. C. Peterson, T. R. Karl, D. E. Parker, M. J. Salinger, V. Razuvayev, N. Plummer, P. Jamason, and C. K. Folland. 1997. Maximum and minimum temperature trends for the globe. Science 277: 364-67.

EPA (U.S. Environmental Protection Agency). 1996. Air Quality Criteria for Ozone and Related Photochemical Oxidants. Volume II. Office of Research and Development.

Etheridge, D. M., L. P. Steele, R. L. Langenfelds, R. J. Francey, J-M. Barnola, and V. I. Morgan. 1996. Natural and anthropogenic changes in atmospheric $\mathrm{CO}_{2}$ over the last 1000 years from air in Antarctic ice and firn. J. Geophys. Res. 101:4115-28.

FAO (United Nations Food and Agriculture Organization). 1996. Production Yearbook, vol. 50. FAO, Rome.

Field, C. B., F. S. Chapin III, N. R. Chiariello, E. A. Holland, and H. A. Mooney. 1996. The Jasper Ridge $\mathrm{CO}_{2}$ experiment: Design and motivation. pp. 121-145. In: G. W. Koch and H. A. Mooney (eds.), Carbon Dioxide and Terrestrial Ecosystems. Academic Press, San Diego, Calif. 
Ford, E. D., and R. O. Teskey. 1991. The concept of closure in calculating carbon balance of forests: Accounting for differences in spatial and temporal scales of components processes. Tree Physiol. 9:307-24.

Gorham, E. 1995. The biogeochemistry of northern peatlands and its possible responses to global warming. pp. 169-87. In G. M. Woodwell and F. T. McKenzie (eds.), Biotic Feedbacks in the Global Climate System. Oxford University Press, New York.

Goulden, M. L., J. W. Munger, S.-M. Fan, B. C. Daube, and S. C. Wofsy. 1996. Exchange of carbon dioxide by a deciduous forest: Response to interannual climate variability. Science 271:1576-78.

Gunderson, C. A., and S. D. Wullschleger. 1994. Photosynthetic acclimation of forest trees to a doubling of atmospheric $\mathrm{CO}_{2}$ : A broader perspective. Photosynth. Res. 39:369-88.

Ham, J. M., C. E. Owensby, P. I. Coyne, and D. J. Bremer. 1995. Fluxes of $\mathrm{CO}_{2}$ and water vapor from a prairie ecosystem exposed to ambient and elevated atmospheric $\mathrm{CO}_{2}$. Agric. For. Meteorol. 77:73-93.

Hanson, P. J., S. D. Wullschleger, L. J. Samuelson, T. A. Tabberer, and G. S. Edwards. 1994. Seasonal patterns of light-saturated photosynthesis and leaf conductance for mature and seedling Quercus rubra L. Foliage: Differential sensitivity to ozone. Tree Physiol. 14:1351-66.

Hanson, P. J., D. E. Todd, M. A. Huston, J. D. Joslin, Jennifer Croker, and R. M. Auge'. 1988. Description and field performance of the Walker Branch Throughfall Displacement Experiment: 1993-1996. ORNL/TM-13586. Oak Ridge National Laboratory, Oak Ridge, Tenn.

Hanson, P. J., D. E. Todd, N. T. Edwards, and M. A. Huston. 1995. Field performance of the Walker Branch Throughfall Displacement Experiment, pp. 307-313. In: A. Jenkins, R. C. Ferrier and C. Kirby (eds.), Ecosystem Manipulation Experiments: Scientific approaches, experimental design and relevant results, Ecosystem Research Report \#20, Commission of the European Communities.

Harte, J., M. S. Torn, F. R. Chang, B. Feifarek, A. P. Kinzig, R. Shaw, and K. Shen. 1995. Global warming and soil microclimate: Results from a meadow-warming experiment. Ecol. Appl. 5(1):132-50.

Hattenschwiler, S., and C. Korner. 1997. Annual $\mathrm{CO}_{2}$ budget of spruce model ecosystems in the third year of exposure to elevated $\mathrm{CO}_{2}$. Acta Oecologia 18:319-25.

Hendrey, G. R., and B. Kimball. 1990. FACE: Free-air carbon dioxide enrichment: application to field-grown cotton. Brookhaven National Laboratory Report 46155. Brookhaven National Laboratory, Upton, N.Y.

Henry, G. H. R., and U. Molau. 1997. Tundra plants and climate change: The International Tundra Experiment (ITEX). Global Change Biology 3:1-9, Suppl. 1.

Houghton, J. T., G. J. Jenkins, and J. J. Ephraums (eds.). 1990. Climate Change: The IPCC Assessment. Cambridge University Press, Cambridge, U.K.

Huston, M. A. 1997. Hidden treatments in ecological experiments: Re-evaluating the ecosystem function of biodiversity. Oecologia 110:449-60.

Idso, S. B., and B. A. Kimball. 1991. Downward regulation of photosynthesis and growth at high $\mathrm{CO}_{2}$ levels. Plant Physiol. 96:990-92. 
IPCC (Intergovernmental Panel on Climate Change). 1996. Climate Change 1995 - Impacts, Adaptations, and Mitigation of Climate Change: Scientific -Technical Analyses. Contribution of Working Group II to the Second Assessment Report of the Intergovernmental Panel on Climate Change. Cambridge University Press, Cambridge, U.K.

IPCC (Intergovernmental Panel on Climate Change). 1998. Regional Impacts of Climate Change: An Assessment of Vulnerability. Intergovernmental Panel on Climate Change, Working Group II Special Report. Cambridge University Press, Cambridge, U.K.

Innes, J. L. 1991. High-altitude and high-latitude tree growth in relation to past, present and future global climate change. Holocene 1:168-73.

Karl, T. R., G. Kukla, and J. Gavin. 1984. Decreasing diurnal temperature range in the United States and Canada from 1941-1980. J. Clim. Appl. Meteorol. 23:1489-1504.

Kauppi, P. E., K. Mielikainen, and K. Kuusela. 1992. Biomass and carbon budget of European forests, 1971-1990. Science 256:70-74.

Keeling, C. D., J. F. S. Chin, and T. P. Whorf. 1996. Increased activity of northern vegetation inferred from atmospheric $\mathrm{CO}_{2}$ measurements. Nature 382:146-49.

Keeling, C. D., and T. P. Whorf. 1997. Atmospheric $\mathrm{CO}_{2}$ concentrations (ppmv) derived from in situ air samples collected at Mauna Loa Observatory, Hawaii. Obtained on-line [http://cdiac.esd.ornl.gov/ftp/ndp001r7/ndp001r7.dat].

Kelly, J. M., L. Samuelson, G. Edwards, P. Hanson, D. Kelting, A. Mays, and S. Wullschleger. 1995. Are seedlings reasonable surrogates for trees? An analysis of ozone impacts on Quercus rubra. Water Air Soil Pollut. 85:1317-24.

Kirschbaum, M. U. F. 1996. Ecophysiological, ecological, and soil processes in terrestrial ecosystems: A primer on general concepts and relationships. pp. 57-92. In R. T. Watson, M. C. Zinyowera, and R. H. Moss (eds.) Climate Change 1995: Impacts, Adaptations and Mitigation of Climate Change: Scientific-Technical Analyses. Cambridge University Press, Cambridge, U.K.

Körner, C., and J. A. Arnone III. 1992. Responses to elevated carbon dioxide in artificial tropical Ecosystems Sci. 257:1672-75.

Landsberg, J. J., M. R. Kaufman, D. Binkley, J. Isebrands, and P. C. Jarvis. 1991. Evaluating progress toward closed forest models based on fluxes of carbon, water, and nutrients. Tree Physiol. 9:1-15.

Long, S. P. 1991. Modification of the response of photosynthetic productivity to rising temperature by atmospheric $\mathrm{CO}_{2}$ concentrations: Has its importance been underestimated? Plant Cell Environ. 14:729-39.

Luxmoore, R. J., P. J. Hanson, J. J. Beauchamp, and J. D. Joslin. Passive nighttime warming facility for forest ecosystem research. Tree Physiol. (in press).

McGuire, A. D., J. M. Melillo, and L. A. Joyce. 1995. The role of nitrogen in the response of forest net primary production to elevated atmospheric carbon dioxide. Annu. Rev. Syst. 26:473-503.

McHale, P. J., and M. J. Mitchell. 1996. Disturbance effects on soil solution chemistry due to heating cable installation. Biol. Fertil. Soil. 22(1-2):40-44.

McLaughlin, S. B., and D. J. Downing. 1996. Interactive effects of ambinent ozone and climate measured on growth of mature loblolly pine trees. Can. J. For. Res. 26:670-81. 
McLaughlin, S. B., J. D. Joslin, W. Robarge, A. Stone, R. Wimmer, and S. D. Wullschleger. 1998. The impacts of acidic deposition and global change on high elevation Southern Appachian spruce-fir forests. Chapter 14 in R. A. Mickler and S. Fox (eds.), The Productivity and Sustainability of Southern Forest Ecosystems in a Changing Environment. Springer-Verlag, Heidelburg, Germany.

Marland, G., B. Andres, and C. Johnston. 1998. Revised global $\mathrm{CO}_{2}$ emissions from fossil-fuel burning, cement manufacture, and gas flaring: 1751-1995. Obtained on-line [http://cdiac.esd.ornl.gov/ftp/ndp030/global95.ems].

Medlyn, B. E., and R. C. Dewar. 1996. A model of the long-term response of carbon allocation and productivity of forests to increased $\mathrm{CO}_{2}$ concentration and nitrogen deposition. Global Change Biol. 2:367-76.

Moldan, F., H. Hultberg, and I. Andersson. 1995. Covered catchment experiment at Gardsjön: Changes in runoff chemistry after four years of experimentally reduced acid deposition. Water Air Soil Pollut. 85:1599-1604.

Mooney, H. A., B. G. Drake, R. J. Luxmoore, W. C. Oechel, and L. F. Pitelka. 1991. Predicting ecosystem responses to elevated $\mathrm{CO}_{2}$ concentrations. BioScience 41:96-104.

Nepstad, D. C., C. R. de Carvalho, E. A. Davidson, P. H. Jipp, P. A. Lefabvre, G. H. Negreiros, E. D. da Silva, T. A. Stone, S. E. Trumbore, and S. Vieira. 1994. The role of deep roots in the hydrological and carbon cycles of Amazonian forests and pastures. Nature 372:666-69.

NRC (National Research Council). 1994. The Role of Terrestrial Ecosystems in Global Change: A Plan for Action. National Academy Press, Washington, D.C.

NRC (National Research Council). 1998. Global Environmental Change: Research Pathways for the Next Decade. National Academy Press, Washington, D.C.

Nicholls, N. 1997. Increased Australian wheat yield due to recent climate trends. Nature 387:484-85.

Norby, R. J., J. Pastor, and J. M. Melillo. 1986. Carbon-nitrogen interactions in $\mathrm{CO}_{2}$-enriched white oak: Physiological and long-term perspectives. Tree Physiol. 2: 233-241.

Norby R. J. 1998. Nitrogen deposition: A component of global change analyses. New Phytol. 139 (in press).

Norby R. J., S. D. Wullschleger, and C. A. Gunderson. 1996. Tree responses to elevated $\mathrm{CO}_{2}$ and the implications for forests. pp. 1-21. In G. W. Koch and H. A. Mooney (eds.), Carbon Dioxide and Terrestrial Ecosystems, Academic Press, San Diego, Calif.

Norby, R. J., N. T. Edwards, J. S. Riggs, C. H. Abner, S. D. Wullschleger, and C. A. Gunderson. 1997. Temperature-controlled open-top chambers for global change research. Global Change Biol. 3:259-67.

Oechel, W. C., and W. D. Billings. 1991. Effect of global change on the carbon balance of arctic plants and ecosystems. pp. 139-168. In F. S. Chapin, R. L. Jefferies, J. F. Reynolds, G. R. Shaver, and J. Svoboda (eds.), Arctic Ecosystems in a Changing Climate. Academic Press, San Diego, Calif.

Olson, J. S., J. A. Watts, and L. J. Allison. 1983. Carbon in Live Vegetation of Major World Ecosystems. ORNL-5862. Oak Ridge National Laboratory, Oak Ridge, Tenn.

Overdieck, D., and M. Forstreuter. 1994. Evapotranspiration of beech stands and transpiration of beech leaves subjected to atmospheric $\mathrm{CO}_{2}$ enrichment. Tree Physiol. 14:997-1003.

Owensby, C. E., P. I. Coyne, J. M. Ham, L. M. Auen, and A. K. Knapp. 1993. Biomass production in a tallgrass prairie ecosystem exposed to ambient and elevated $\mathrm{CO}_{2}$. Ecol. Appl. 3:644-53. 
Owensby, C. E., J. M. Ham, A. K. Knapp, D. Bremer, and L. M. Auen. 1997. Water vapor fluxes and their impact under elevated $\mathrm{CO}_{2}$ in a C4-tallgrass prairie. Global Change Biol. 3:189-95.

Parton, W. J., D. S. Schimel, C. V. Cole, and D. S. Ojima. 1987. Analysis of factors controlling soil organic matter levels in Great Plains grasslands. Soil Sci. Soc. Am. J. 51:1173-1179.

Pastor, J., and W. M. Post. 1988. Response of northern forests to $\mathrm{CO}_{2}$-induced climate change. Nature 334:55-58.

PCAST (President's Committee of Advisors on Science and Technology). 1998. Teaming with Life: Investing in Science to Understand and Use America's Living Capital. PCAST Panel on Biodiversity and Ecosystems. Executive Office of the President, Washington, D.C.

Peterjohn, W. T., J. M. Mellilo, F. P. Bowles, and P. A. Steudler. 1993. Soil warming and trace4 gas fluxes: Experimental design and preliminary flux results. Oecologia 93:18-24.

Prentice, I. C., R. S. Webb, M. Ter-Mikhaelian, A. M. Solomon, T. M. Smith, S. E. Pitrovranov, N. Nikolov, A. A. Minin, R. Leemans, S. Lavorel, M. D. Korzukhin, J. P. Hrabovszky, H. O. Helmisaari, S. P. Harrison, W. R. Emanuel, and G. B. Bonan. 1989. Developing a global vegetation dynamics model: Results of an IIASA summer workshop. International Institute for Applied Systems Analysis; Laxenburg, Austria.

Post, W. M., W. R. Emanuel, P. J., Zinke, and A. G. Stangenberger. 1982. Soil carbon pools and world life zones. Nature 298:156-159.

Quay, P. D., B. Tilbrook, and C. S. Wong. 1992. Oceanic uptake of fossil fuel $\mathrm{CO}_{2}$ : Carbon-13 evidence. Science 256:74-79.

Ruimy, A., C. B. Field, D. Herbert, R. Kelly, R. E. McMurtrie, W. J. Parton, L. L. Pierce, and CMEAL $\left[\mathrm{CO}_{2}\right.$ Models/Experiments Activity for improved Links] participants. 1998. Forest and grassland responses to elevated atmospheric $\mathrm{CO}_{2}$ : Resource use factors from four ecosystem models. Paper 0017 available on-line [http://jasper.stanford.edu/GCTE/LUCC/theme1.html].

Running, S. W., R. R. Nemani, D. L. Peterson, L. E. Band, D. F. Potts, L. L. Pierce, and M. A. Spanner. 1989. Mapping regional forest evapotranspiration and photosynthesis by coupling satellite data with ecosystem simulation. Ecology 70:1090-1101.

Schapendonk, A. H. C. M., P. Dijkstra, J. Groenwold, C. S. Pot, and S. C. Van de Geijn. 1997. Carbon balance and water use efficiency of frequently cut Lolium perenne L. swards at elevated carbon dioxide. Global Change Biol. 3:207-16.

Tans, P. P., I. Y. Fung, and T. Takahashi. 1990. Observational constraints on the global atmospheric $\mathrm{CO}_{2}$ budget. Science 247:1431-38.

USGCRP (U.S. Global Change Research Program). 1997. Out Changing Planet: An investment in science for the Nation's future. A Report by the Subcommittee on Global Change Research, Committee on Environment and Natural Resources Research of the National Science and Technology Council. Washington, D.C.

VEMAP Members. 1995. Vegetation/Ecosystem Modeling and Analysis Project (VEMAP): Comparing biogeography and biogeochemistry models in a continental-scale study of terrestrial ecosystem responses to climate change and $\mathrm{CO}_{2}$ doubling. Global Biogeochem. Cycles 9(4):407-37.

Walker, J. C. G., and J. F. Kasting. 1992. Effects of fuel and forest conservation on future levels of atmospheric carbon dioxide. Palaeogeography, Palaeoclimatology, Palaeoecology (Global Planetary Change Section) 97:151-89.

Wang, Y.-P., A. Rey, and P. G. Jarvis. 1998. Carbon balance of young birch trees grown in ambient and elevated atmospheric $\mathrm{CO}_{2}$ concentrations. Global Change Biol. (in press). 
Wullschleger, S. D., R. J. Norby, and C. A. Gunderson. 1997. Forest trees and their response to atmospheric $\mathrm{CO}_{2}$ enrichment: A compilation of results. pp. 79-100 In: L. H. Allen, Jr. (ed.), Advances in Carbon Dioxide Effects Research, ASA Special Publication no. 61, American Society of Agronomy, Madison, Wis.

Zak, D. R., K. S. Pregitzer, P. S. Curtis, J. A. Teeri, R. Fogel, and D. L. Randlett. 1993. Elevated atmospheric $\mathrm{CO}_{2}$ and feedback between carbon and nitrogen cycles. Plant Soil 151:105-17. 

ORNL/TM-1998/27

\section{INTERNAL DISTRIBUTION}

1. J. S. Amthor

2. J. H. Cushman

3. V. H. Dale

4. N. T. Edwards

5. M. P. Farrell

6. C. T. Garten

7. C. A. Gunderson

8. P. J. Hanson

9-267. S. G. Hildebrand

268. M. A. Huston

269. G. K. Jacobs

270. P. Kanciruk

271. A. W. King

272. J. M. Loar

273. R. J. Luxmoore

274. G. Marland

275. S. B. McLaughlin
276. P. J. Mulholland

277. R. J. Norby

278. E. G. O'Neill

279. R. V. O'Neill

280. W. M. Post

281. D. E. Reichle

282. D. S. Shriner

283. D. E. Todd

284. T. J. Tschaplinski

285. R. S. Turner

286. G. A. Tuskan

287. S. D. Wullschleger

288. Central Research Library

289-91. ESD Library

292. Laboratory Records Dept.

293. Laboratory Records, ORNL-RC

294. ORNL Patent Section

\section{EXTERNAL DISTRIBUTION}

295. M. Broido, Director, Environmental Sciences Division, ER-74, Department of Energy, 19901 Germantown Road, Germantown, MD 20874

296. E. G. Cumesty, Assistant Manager for Laboratories and Site Manager, Department of Energy, Oak Ridge National Laboratory Site Office, P.O. Box 2008, Oak Ridge, TN 37831-6269

297-396. Roger Dahlman, Office of Biological and Environmental Division, ER-74, Department of Energy, 19901 Germantown Road, Germantown, MD 20874

397-496. J. Elwood, Office of Biological and Environmental Division, ER-74, Department of Energy, 19901 Germantown Road, Germantown, MD 20874

497. G. Hendry, Brookhaven National Laboratory, Department of Applied Science, Bldg. 318, P.O. Box 5000, Upton, NY 11973

498. Michael C. MacCracken, Director, Office of the U.S. Global Change Research Program, Code YS-1, 300 E Street, SW, Washington, DC 20546

499. A. Patrinos, Office of Biological and Environmental Division, ER-74, Department of Energy, 19901 Germantown Road, Germantown, MD 20874

500. Office of Scientific and Technical Information, P.O. Box 62, Oak Ridge, TN 37831 